\title{
Defective expression of SIRT1 contributes to sustain inflammatory pathways in the gut
}

\author{
R Caruso $^{1}$, I Marafini $^{1}$, E Franzè $^{1}$, C Stolfi $^{1}$, F Zorzi $^{1}$, I Monteleone $^{1}$, F Caprioli $^{2}$, A Colantoni $^{1}$, M Sarra $^{1}$, \\ S Sedda ${ }^{1}$, L Biancone ${ }^{1}$, P Sileri ${ }^{3}$, GS Sica ${ }^{3}$, TT MacDonald ${ }^{4}$, F Pallone ${ }^{1}$ and G Monteleone ${ }^{1}$
}

In inflammatory bowel disease (IBD), tissue damage is driven by an excessive immune response, poorly controlled by counter-regulatory mechanisms. SIRT1, a class III NAD + -dependent deacetylase, regulates negatively the expression of various proteins involved in the control of immune-inflammatory pathways, such as Stat3, Smad7, and NF-kB. Here we examined the expression, regulation, and function of SIRT1 in IBD. SIRT1 RNA and protein expression was less pronounced in whole biopsies and lamina propria mononuclear cells (LPMCs) of IBD patients in comparison with normal controls. SIRT1 expression was downregulated in control LPMC by tumor necrosis factor (TNF)- $\alpha$ and interleukin (IL)-21, and upregulated in IBD LPMC by neutralizing TNF- $\alpha$ and IL-21 antibodies. Consistently, SIRT1 expression was increased in mucosal samples taken from IBD patients successfully treated with Infliximab. Treatment of IBD LPMC with Cay10591, a specific SIRT1 activator, reduced NF-KB activation and inhibited inflammatory cytokine synthesis, whereas Ex527, an inhibitor of SIRT1, increased interferon (IFN)- $\gamma$ in control LPMC. SIRT1 was also reduced in mice with colitis induced by 2,4,6-trinitrobenzenesulphonic acid or oxazolone. Cay10591 prevented and cured experimental colitis whereas Ex527 exacerbated disease by modulating Tcell-derived cytokine response. Data indicate that SIRT1 is downregulated in IBD patients and colitic mice and suggest that SIRT1 activation can help attenuate inflammatory signals in the gut.

\section{INTRODUCTION}

Although the etiology of both Crohn's disease (CD) and ulcerative colitis (UC), the major forms of inflammatory bowel disease (IBD) in human beings, remain unknown, compelling evidence indicates that it is likely that IBD-associated tissue damage is due to a dynamic interaction between genetic and environmental factors, which promotes an excessive mucosal immune response directed against components of the normal microflora. ${ }^{1-3}$ Although many immune cell types infiltrate the IBD mucosa, a large body of evidence indicates that $T$ cells have a major role in the tissue damage by secreting elevated levels of cytokines, which can target both immune and nonimmune cells thus amplifying the ongoing mucosal inflammation. ${ }^{4,5}$ It is also apparent that IBD-associated inflammation is amplified and maintained by the defective activity of counter-regulatory mechanisms. ${ }^{3}$ Therefore restoring the balance between effector and anti-inflammatory molecules is now considered as a valid therapeutic strategy to control inappropriate immune responses in IBD.
The mammalian Sirtuin family proteins, initially identified as orthologs of the yeast sir2 (silent information regulatory 2), have seven members, Sirt1 to Sirt7. Like sir2, Sirtuins possess $\mathrm{NAD}+$-dependent deacetylase activity targeting histones $\mathrm{H} 1$, $\mathrm{H} 3$, and $\mathrm{H} 4$ as well as a plethora of nonhistone substrates. ${ }^{6-9}$ SIRT1 is highly expressed in heart, brain, and skeletal muscle, and also at very low levels in kidney and lung, and has diverse functions in a variety of physiological processes, from cancer to mitochondrial biogenesis to angiogenesis. ${ }^{10,11}$ SIRT1 deacetylates the lysine residues of various proteins, which have a role in the progression of immune-inflammatory processes, such as the transcription factors Stat 3 and NF-KBp65, c-Jun (a component of the transcription factor AP-1), and Smad7, an inhibitor of TGF- $\beta 1$ activity. As the SIRT1-induced deacetylation facilitates their ubiquitination and proteasome-mediated degradation, SIRT1 can act as an inhibitor of inflammatory signals, at least in specific cell types. Indeed, it has recently been demonstrated that SIRT1 negatively regulates $\mathrm{T}$ cell, and loss of SIRT1 function results in breakdown

1Department of Systems Medicine, University of Rome "Tor Vergata”, Rome, Italy. 'Unit of Gastroenterology, Fondazione IRCCS Ca' Granda-Ospedale Maggiore Policlinico, Milan, Italy. ${ }^{3}$ Department of Surgery, University of Rome "Tor Vergata", Rome, Italy; and ${ }^{4}$ Barts and the London School of Medicine and Dentistry, London, UK. Correspondence: G Monteleone (Gi.Monteleone@Med.uniroma2.it)

Received 8 October 2013; accepted 15 April 2014; published online 21 May 2014. doi:10.1038/mi.2014.35 
of $\mathrm{T}$ cell tolerance and development of immune-mediated diseases. ${ }^{12,13}$ The present study was aimed at determining the expression and role of SIRT1 in IBD and experimental models of colitis.

\section{RESULTS}

SIRT1 but not SIRT2 transcripts are downregulated in IBD To evaluate the expression of SIRT1 in the human gut, colonic biopsies taken from patients with $\mathrm{CD}$, patients with UC, patients with diverticular disease, and normal controls were analyzed for SIRT1 by real-time PCR. SIRT1 transcripts were significantly reduced in both $\mathrm{CD}$ and UC compared with controls, with no difference between CD and UC (Figure 1a). SIRT1 transcripts were also downregulated in patients with diverticular disease compared with normal controls (Figure 1a). In IBD, downregulation of SIRT1 was seen in both patients receiving no therapy and those taking mesalamine, corticosteroids, or immunomodulators (Figure 1b) and was restricted to the areas of active inflammation (Figure 1c). Reduced SIRT1 RNA expression was also seen in ileal CD samples compared with normal ileal samples (Figure 1d). Interestingly, no downregulation of SIRT1 was seen in duodenal biopsies of patients with active celiac disease compared with normal duodenal samples (Figure 1e). In contrast, SIRT2 transcripts, another member of the Sirtuin family, did not differ between IBD patients and controls (Figure 1f).

\section{SIRT1 protein expression is reduced in IBD tissue}

Next, we examined SIRT1 protein expression in whole biopsy specimens of IBD and controls by western blotting. Immunoreactive bands corresponding to SIRT1 were evident in all control and IBD samples (Figure 2a). However, expression of SIRT1 was significantly decreased in both UC and CD samples compared with controls (Figure 2a). Further analysis of SIRT1 in total proteins extracted from lamina propria mononuclear cells (LPMCs) samples confirmed the decreased expression of SIRT1 in IBD compared with controls (Figure 2b). To determine which LPMC subpopulations express SIRT1, we initially performed a double immunofluorescence on control colonic sections, but we were not able to identify cell sources of SIRT1 using different commercial antibodies. Therefore, we next assessed SIRT1 in $\mathrm{CD}^{+}{ }^{+}, \mathrm{CD} 19^{+}$, and HLA-DRII ${ }^{+}$cells purified from colonic LPMC by flow cytometry. More than two-thirds of $\mathrm{CD}^{+}$cells and $\mathrm{CD} 19^{+}$cells and nearly half of HLA-DRII $^{+}$cells from controls expressed SIRT1 (Figure 2c, left panels). SIRT1 expression was reduced in each of these LPMC subpopulations in both UC and CD compared with control samples (Figure 2c, middle and right panels). SIRT1
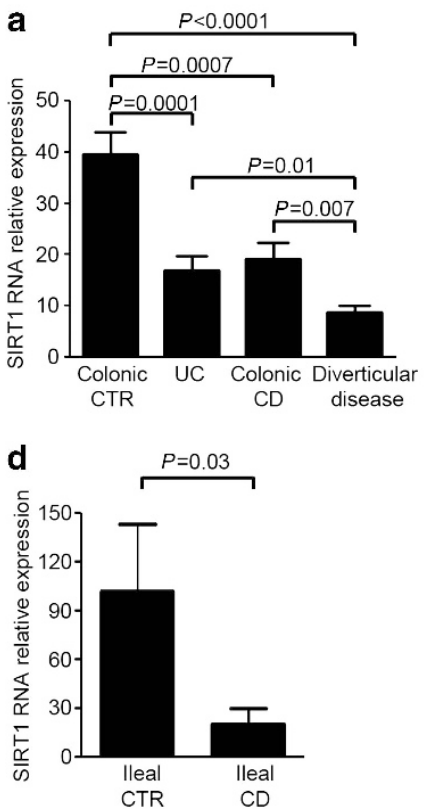

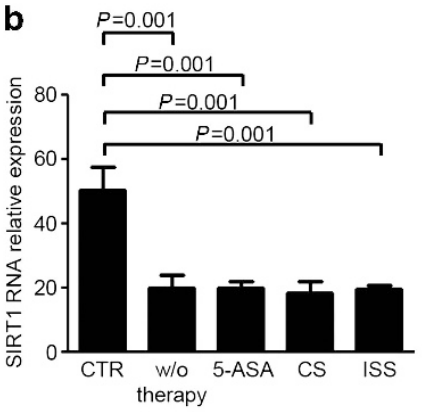

C

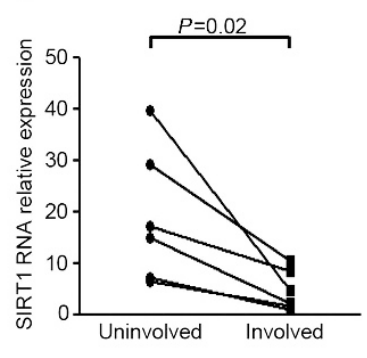

f

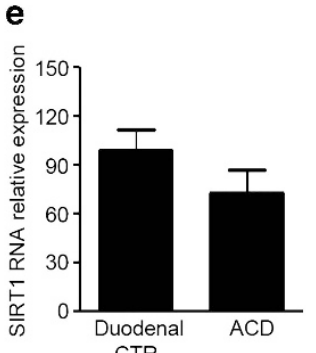

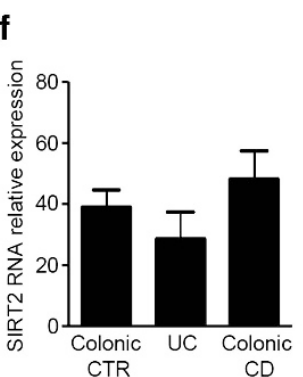

Figure 1 SIRT1 transcripts are downregulated in inflamed IBD mucosa. (a) SIRT1 RNA expression was evaluated in colonic biopsies taken from 21 normal controls (CTR), 29 patients with ulcerative colitis (UC), 28 patients with Crohn's disease (CD), and 4 patients with diverticular disease by real-time PCR and levels were normalized to $\beta$-actin. Data indicate mean \pm s.e.m. of all the samples. (b) Colonic biopsies taken from 21 CTR, 13 IBD patients (7 CD and $6 \mathrm{UC}$ ) receiving no therapy (w/o therapy), 24 IBD patients ( $8 \mathrm{CD}$ and $16 \mathrm{UC}$ ) treated with mesalamine, 15 IBD patients (6 CD and $9 \mathrm{UC})$ treated with corticosteroids and $10 \mathrm{IBD}$ patients $(9 \mathrm{CD}$ and $1 \mathrm{UC}$ ) treated with immunomodulators (ISS) were analyzed for SIRT1 RNA expression by real-time PCR. Levels are normalized to $\beta$-actin. Data are expressed as mean \pm s.e.m. of all the samples. (c) Paired biopsies taken from the involved and uninvolved mucosa of four UC patients and two CD patients were analyzed for SIRT1 RNA expression by real-time PCR. Levels are normalized to $\beta$-actin and each point represents the value of SIRT1 RNA relative expression in mucosal samples taken from a single subject. (d) SIRT1 RNA expression was evaluated in ileal biopsies taken from five ileal CTR and seven ileal CD patients by real-time PCR. Data indicate mean \pm s.e.m. of all the samples. (e) SIRT1 RNA expression was evaluated in duodenal biopsies taken from eight normal controls (CTR), nine patients with active celiac disease (ACD) by real-time PCR, and levels were normalized to $\beta$-actin. Data indicate mean \pm s.e.m. of all the samples. (f) SIRT2 RNA expression was evaluated in colonic biopsies taken from seven normal controls (CTR), seven patients with ulcerative colitis (UC), and seven patients with Crohn's disease (CD) by real-time PCR and levels were normalized to $\beta$-actin. Data indicate mean \pm s.e.m. of all the samples. 
a

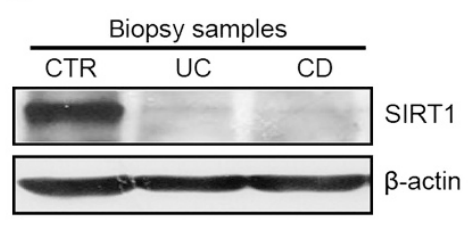

b

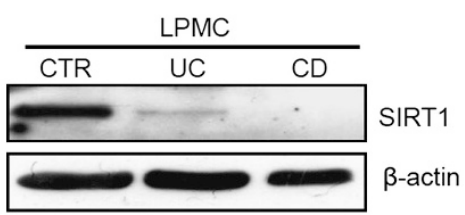

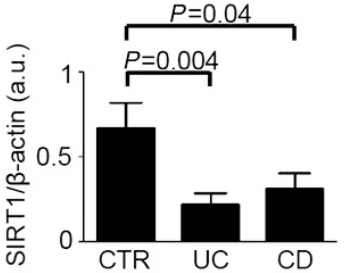

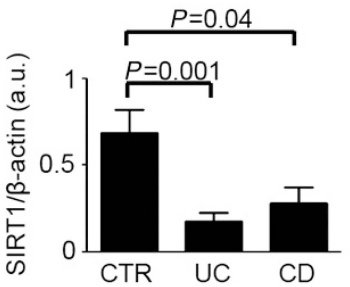

c

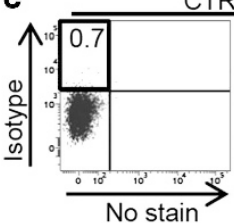

CTR CD3+ cells

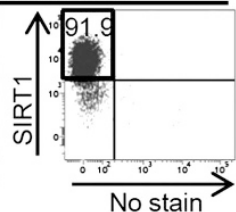

CTR CD19+ cells
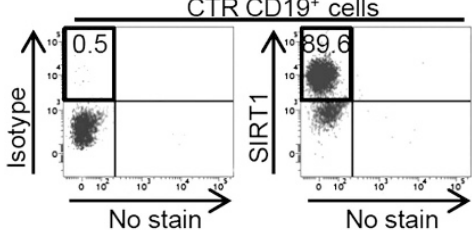

CTR HLA-DR ${ }^{+}$cells
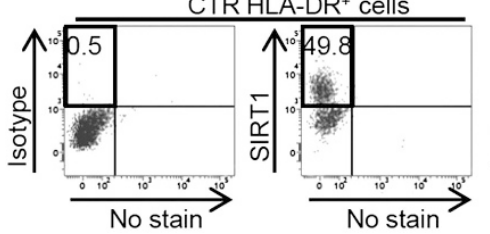

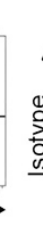

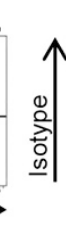

UC CD3 ${ }^{+}$cells

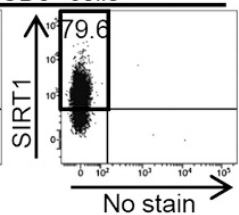

UC $\mathrm{CD}^{+}$cells

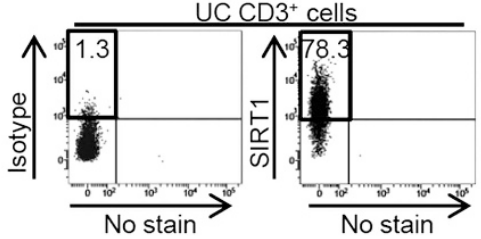

UC HLA-DR ${ }^{+}$cells
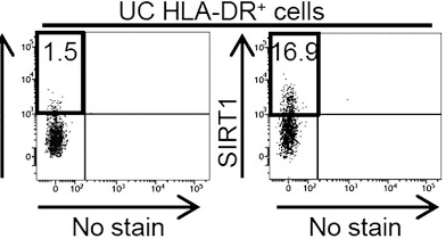
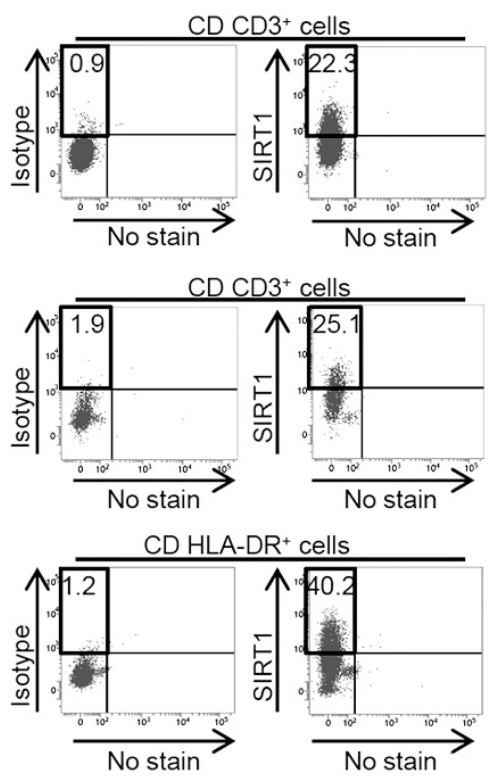

Figure 2 SIRT1 protein expression is reduced in IBD tissue. (a) Representative western blots showing SIRT1 and $\beta$-actin in total proteins extracted from mucosal samples of one CTR, one UC patient, and one CD patient. Right panel shows the quantitative analysis of SIRT1/ $\beta$-actin ratio in mucosal samples taken from 7 CTR, $10 \mathrm{UC}$ patients, and $10 \mathrm{CD}$ patients as measured by densitometry scanning of western blots. Values are expressed in arbitrary units (a.u.) and indicate mean \pm s.e.m. of all samples. (b) Representative western blots showing SIRT1 and $\beta$-actin in total proteins extracted from LPMC isolated from one CTR, one UC patient, and one CD patient. Right panel shows the quantitative analysis of SIRT1/ $\beta$-actin ratio in LPMC protein extracts taken from six CTR, four UC patients, and four CD patients as measured by densitometry scanning of western blots. Values are expressed in arbitrary units (a.u.) and indicate mean \pm s.e.m. of all the samples. (c) Representative dot plots of SIRT1 in lamina propria CD3 ${ }^{+}, \mathrm{CD}_{19}{ }^{+}$, and HLA-DRII ${ }^{+}$cells isolated from one CTR, one UC patient, and one CD patient. Numbers in quadrants indicate the percentages of SIRT1-espressing cells. Staining with a nonrelevant isotype lgG is also shown. One of three independent experiments in which similar results were obtained is shown. CD, Crohn's disease; CTR, control; LPMC, lamina propria mononuclear cell; UC, ulcerative colitis.

staining in blood $\mathrm{CD}^{+}, \mathrm{CD}^{+} 9^{+}$, and HLA-DRII ${ }^{+}$cells confirmed the downregulation of the protein in control samples (Supplementary Figure 1 online). Taken together these data indicate that SIRT1 expression is diminished in both CD and UC, raising the possibility that such a defect contributes to amplify/maintain the ongoing inflammatory response in IBD.

\section{SIRT1 expression is downregulated by TNF- $\alpha$ and IL-21}

The demonstration that SIRT1 is downregulated in UC and CD prompted us to examine whether it is negatively regulated by some of the inflammatory cytokines produced in excess in IBD. ${ }^{5}$ SIRT1 RNA expression was downregulated in control LPMC by TNF- $\alpha$ and IL-21, but neither by IFN- $\gamma$ nor by IL17A (Figure 3a). Western blotting experiments confirmed the reduced expression of SIRT1 in control LPMC stimulated with TNF- $\alpha$ and IL-21 (Figure 3b). Consistently, neutralization of TNF- $\alpha$ or IL-21 in IBD LPMC cultures enhanced SIRT1 (Figure 3c). Moreover, SIRT1 transcripts were significantly upregulated in colonic samples taken from IBD patients successfully treated with Infliximab (IFX) (Figure 3d), whereas no significant change in SIRT1 RNA expression was seen in IBD patients who failed to IFX therapy (Figure 3e).

\section{Cay10591, an agonist of SIRT1, reduces NF-kB activation and suppresses inflammatory cytokine expression in IBD LPMC}

Studies carried out in other cell systems have previously shown that SIRT1 modulates the acetylation status of the RelA/p65 

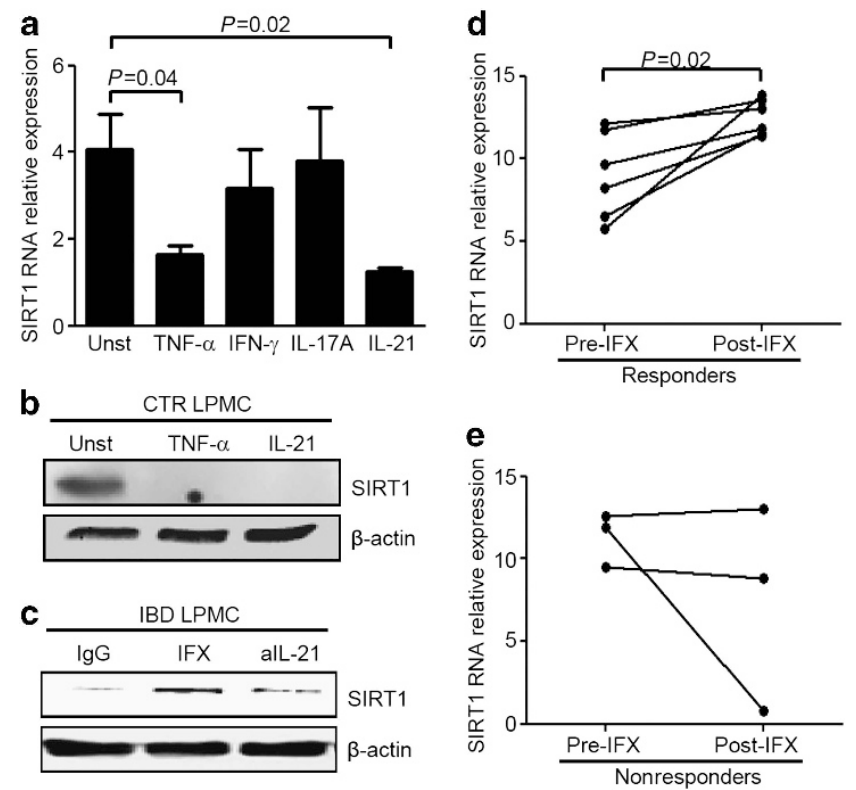

Figure 3 TNF- $\alpha$ and IL-21 reduce SIRT1 in the gut. (a) Control LPMC were cultured with or without (Unst, unstimulated), TNF- $\alpha\left(20 \mathrm{ng} \mathrm{ml}^{-1}\right)$, IFN- $\gamma\left(100 \mathrm{ng} \mathrm{ml}^{-1}\right), \mathrm{IL}-21\left(50 \mathrm{ng} \mathrm{ml}^{-1}\right)$, and IL-17 A $\left(20 \mathrm{ng} \mathrm{ml}^{-1}\right)$ for $6 \mathrm{~h}$, and SIRT1 RNA expression was analyzed by real-time PCR. Data indicate mean \pm s.e.m. of the three independent experiments. (b) Representative western blots showing SIRT1 and $\beta$-actin in total proteins extracted from control LPMC treated as indicated above for $24 \mathrm{~h}$. One of three independent experiments in which similar results were obtained is shown. Blockade of both TNF- $\alpha$ and IL-21 enhanced SIRT1 expression in IBD LPMC. (c) Representative western blots showing SIRT1 and $\beta$-actin in total proteins extracted from IBD LPMC cultured with Infliximab (IFX), with a neutralizing anti-IL-21 antibody (alL-21) or control IgG (IgG) for $48 \mathrm{~h}$. One of three independent experiments in which similar results were obtained is shown. (d) SIRT1 RNA expression was evaluated in colonic biopsies taken from three UC patients and three CD patients before and after a successful Infliximab (IFX) treatment by real-time PCR. Levels were normalized to $\beta$-actin and each point represents the value of SIRT1 RNA relative expression in mucosal samples taken from a single subject. (e) SIRT1 RNA expression was evaluated in colonic biopsies taken from one UC patient and two CD patients before and after an unsuccessful Infliximab (IFX) treatment by real-time PCR. Levels were normalized to $\beta$-actin and each point represents the value of SIRT1 RNA relative expression in mucosal samples taken from a single subject. CD, Crohn's disease; CTR, control; IBD, inflammatory bowel disease; IL, interleukin; LPMC, lamina propria mononuclear cell; UC, ulcerative colitis; TNF, tumor necrosis factor.

subunit of NF- $\kappa \mathrm{B},{ }^{14}$ a transcription factor which is overactivated in IBD tissue and supposed to contribute to sustain inflammatory cytokine production. ${ }^{15,16}$ Thus, we examined whether SIRT1 could control the acetylation of NF-кBp65 in IBD LPMC. IBD LPMC were pre-incubated with Cay10591 or dimethyl sulfoxide (DMSO) for $1 \mathrm{~h}$ and then stimulated with activating anti-CD3/CD28 antibody-coated beads. After $16 \mathrm{~h}$, cell extracts were immunoprecipitated with anti-NF- $\mathrm{\kappa Bp} 65$ and probed with anti-acetyl-lysine antibody. Cay10591 reduced the acetylation of NF- $\mathrm{KBp} 65$ in IBD LPMC and this was associated with enhanced ubiquitination of NF- $\mathrm{\kappa Bp} 65$ in the same cells (Figure 4a). Consistently, the total protein content of NF-KBp65 was reduced in Cay10591-treated IBD LPMC (Figure $4 \mathbf{b}$ ) as well as was NF- $\kappa B$ activation (Figure $4 \mathbf{c}$ ).

We next examined whether treatment of IBD LPMC with graded doses of Cay10591 inhibited inflammatory cytokines.
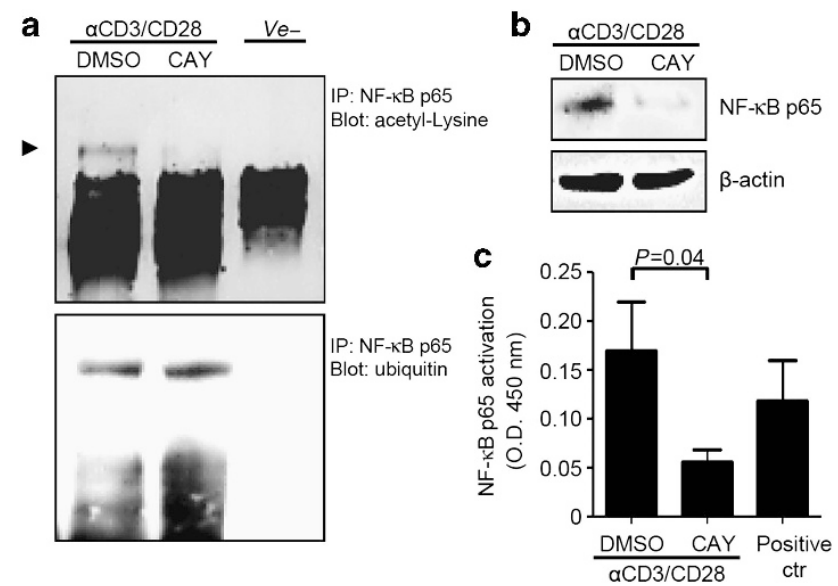

Figure 4 Cay10591 reduces NF-kBp65 activation in IBD. (a) Representative blot showing acetylated (upper panel) and ubiquitinated (lower panel) NF-kBp65 in IBD LPMC pre-incubated with Cay10591 or dimethyl sulfoxide (DMSO) for $1 \mathrm{~h}$ and then stimulated with activating antiCD3/CD28 antibody-coated beads for further $16 \mathrm{~h}$. Proteins were immunoprecipitated by an anti-human NF-kBp65 or control isotype ( $\mathrm{Ve}-$ ) antibody and then subjected to immunoblot analysis using an anti-acetyllysine antibody. After analysis of acetylated NF-кBp65, the blot was stripped and incubated with an anti-ubiquitin antibody. (b) Representative western blots showing NF- $\mathrm{KBp} 65$ and $\beta$-actin in total proteins extracted from IBD LPMC treated as indicated above for $16 \mathrm{~h}$. (c) NF-kBp65 activation was assessed using ELISA-based TransAM assay in protein extracts of IBD LPMC pre-incubated with Cay 10591 or DMSO for $1 \mathrm{~h}$ and then stimulated with activating anti-CD3/CD28 antibody-coated beads for further $16 \mathrm{~h}$. Protein extracts of Jurkat cells were used as positive control (Positive ctr).Values are expressed in optical density (O.D.) and indicate mean \pm s.e.m. of all the samples. ctr, control; ELISA, enzyme-linked immunosorbent assay; IBD, inflammatory bowel disease; LPMC, lamina propria mononuclear cell; $\mathrm{Ve}-$, negative control.

These studies were focused on IFN- $\gamma$, IL-17A, and IL-21 because $\mathrm{CD}$-associated inflammation is characterized by enhanced production of Th1/Th17-related cytokines. ${ }^{17-20}$ Real-time PCR showed that Cay10591 inhibited anti-CD3/ CD28-induced IFN- $\gamma$ RNA expression in CD LPMC. As the maximal inhibitory effects of Cay10591 were seen with concentrations of $10 \mu \mathrm{M}$ (not shown), we selected this dose for the subsequent experiments. Cay10591 significantly inhibited the RNA transcripts of IFN- $\gamma$, IL-17A, and IL-21 in CD LPMC (Figure 5a). Flow cytometry analysis confirmed that the treatment of CD LPMC with Cay10591 significantly reduced the fractions of IFN- $\gamma$ and IL-17A-expressing cells (Figure 5b). Subsequently, we evaluated whether Cay10591 inhibited the expression of IL-13, IL-17A, and IL-21 in UC LPMC, because these cytokines are highly produced in the inflamed colon of UC patients. ${ }^{17,21}$ Cay10591 significantly reduced RNA transcripts of all the cytokines (Figure 5c) as well as the percentage of IL-17A-producing $\mathrm{CD}^{+}$cells in UC (Figure 5d).

In line with the above data, treatment of control LPMC with Ex527, an inhibitor of SIRT1, significantly enhanced anti-CD3/ CD28-induced IFN- $\gamma$ RNA expression (Figure 5e) and the percentage of IFN- $\gamma$-expressing cells (Figure 5f). Neither Cay10591 nor EX527 changed the fraction of annexin V/propidium iodide-positive LPMC (not shown). 

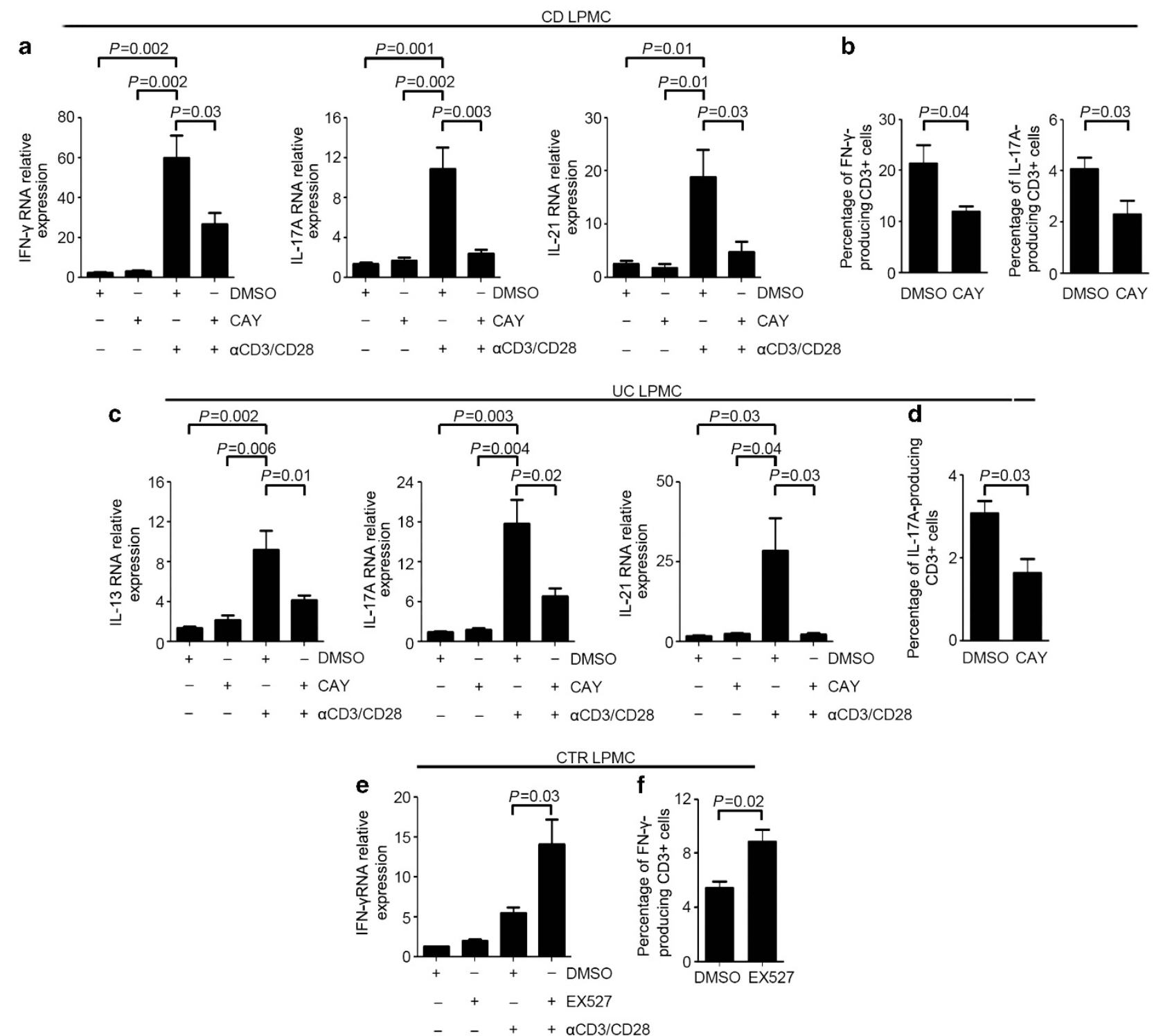

Figure 5 SIRT1 inhibits the expression of inflammatory cytokines in IBD LPMC. (a) LPMC were isolated from six CD patients and pre-incubated with Cay10591 (CAY, $10 \mu \mathrm{m}$ ) or dimethyl sulfoxide (DMSO, vehicle) for $1 \mathrm{~h}$, then either cultured with medium or activating anti-CD3/CD28 antibody-coated beads for further $6 \mathrm{~h}$. RNA was extracted and amplified by real-time PCR. Levels are normalized to $\beta$-actin and indicate the mean \pm s.e.m. of all the experiments. (b) LPMC, isolated from six CD patients, were pre-incubated with Cay10591 (CAY, $10 \mu \mathrm{M}$ ) or DMSO (vehicle) for $19 \mathrm{~h}$ and then stimulated with Phorbol 12-myristate 13-acetate $\left(40 \mathrm{ng} \mathrm{ml}^{-1}\right)$, ionomycin $\left(1 \mu \mathrm{g} \mathrm{ml}^{-1}\right)$, and monensin $\left(2 \mu \mathrm{mol} \mathrm{I}^{-1}\right)$ for further $5 \mathrm{~h}$ and analyzed by flow cytometry. Representative histograms show the percentage of IFN $\gamma$ - and IL-17A-producing CD3 ${ }^{+} \mathrm{T}$ cells. Data indicate mean \pm s.e.m. of all the experiments. (c) LPMC were isolated from four UC patients and pre-incubated with Cay10591 (CAY, $10 \mu \mathrm{M}$ ) or DMSO (vehicle) for $1 \mathrm{~h}$, then either cultured with medium or activating anti-CD3/CD28 antibody-coated beads for further $6 \mathrm{~h}$. RNA was extracted and amplified by real-time PCR. Levels are normalized to $\beta$-actin and indicate the mean \pm s.e.m. of all the experiments. (d) LPMC, isolated from three UC patients, were pre-incubated with Cay 10591 (CAY, $10 \mu \mathrm{M}$ ) or DMSO (vehicle) for $19 \mathrm{~h}$ and then stimulated with Phorbol 12 -myristate 13 -acetate $\left(40 \mathrm{ng} \mathrm{ml}^{-1}\right)$, ionomycin $\left(1 \mu \mathrm{g} \mathrm{ml}^{-1}\right)$, and monensin $\left(2 \mu \mathrm{moll} \mathrm{I}^{-1}\right)$ for further $5 \mathrm{~h}$ and analyzed by flow cytometry. Representative histograms show the percentage of IL-17A-producing CD3 ${ }^{+} \mathrm{T}$ cells. Data indicate mean \pm s.e.m. of all the experiments. (e) LPMC were isolated from five CTR patients and pre-incubated with EX527 (10 $\mu \mathrm{M})$ or DMSO (vehicle)for $1 \mathrm{~h}$, then either cultured with medium or activating anti-CD3/CD28 antibody-coated beads for further $6 \mathrm{~h}$. RNA was extracted and amplified by real-time PCR. Levels are normalized to $\beta$-actin and indicate the mean \pm s.e.m. of all the experiments. (f) LPMC, isolated from three CTR, were pre-incubated with EX527 (100 $\mu \mathrm{M}$ ) or DMSO (vehicle) for $19 \mathrm{~h}$ and then stimulated with Phorbol 12-myristate 13-acetate $\left(40 \mathrm{ng} \mathrm{ml}^{-1}\right)$, ionomycin $\left(1 \mu \mathrm{g} \mathrm{ml}^{-1}\right)$, and monensin $\left(2 \mu \mathrm{moll} \mathrm{I}^{-1}\right)$ for further $5 \mathrm{~h}$, and analyzed by flow cytometry. Representative histograms show the percentage of IFN $\gamma$-producing CD3 ${ }^{+} \mathrm{T}^{\mathrm{T}}$ cells. Data indicate mean $\pm \mathrm{s}$.e.m. of all the experiments. CD, Crohn's disease; CTR, control; IBD, inflammatory bowel disease; IFN, interferon; IL, interleukin; LPMC, lamina propria mononuclear cell; UC, ulcerative colitis; TNF, tumor necrosis factor.

\section{Cay10591 prevents and Ex527 exacerbates TNBS-induced colitis}

2,4,6-trinitrobenzenesulphonic acid (TNBS)-colitis was induced in SJL mice and SIRT1 expression was evaluated in colonic samples by real-time PCR and western blotting.
Transcripts of SIRT1 were significantly reduced in the colon of TNBS-treated mice compared with controls (Figure 6a). Immunoreactive bands corresponding to SIRT1 were evident in all control and colitic mice (Figure 6b). However, expression of SIRT1 was significantly decreased in TNBS-treated mice 
compared with controls (Figure 6b). Kinetics of SIRT1 expression during colitis showed that downregulation of SIRT1 occurred at early time points (i.e., day 2 ) and persisted over time (Figure 6c).

The demonstration that SIRT1 controls production of inflammatory cytokines in CD LPMC cultures prompted us to explore whether Cay10591 could inhibit CD-like TNBSmediated Th1-driven colonic inflammation in vivo in mice. To this end, we initially showed that treatment of LPMC isolated from TNBS-treated mice with Cay10591 significantly reduced anti-CD3/CD28-induced IFN- $\gamma$ and LPS-triggered TNF- $\alpha$ RNA expression (Figure 7a). Next, mice were given $4.5 \mathrm{mg} \mathrm{kg}^{-1}$ Cay10591 (or DMSO) by oral gavage $24 \mathrm{~h}$ before TNBS administration for prophylactic effects. Mice were killed at day 4 and colons were collected and used for histology and cytokine analysis. Histopathologically,
TNBS-treated mice receiving DMSO had a more severe colitis than Cay10591-treated mice (Figure 7b). Consistently, mice given Cay10591 had lower RNA and protein levels of IFN- $\gamma$, a cytokine involved in the pathogenesis of TNBS-colitis, than control mice (Figure $7 \mathrm{c})^{22}$ and reduced mucosal infiltration of $\mathrm{CD} 3^{+} \mathrm{T}$ cells (Supplementary Figure 2A, left panel) but no change in the mucosal infiltration of $\mathrm{F} 4 / 80^{+}$cells (Supplementary Figure 2A, right panel). Finally, we tested the therapeutic effects of Cay10591 in TNBS-colitis by treating $24 \mathrm{~h}$ after induction of colitis. Histological examination of colonic tissues as well as blinded histologic scoring of colitis showed that the inflammation was significantly reduced in Cay10591-treated mice (Figure 7d). Mice treated with Cay10591 produced less IFN- $\gamma$ and had reduced mucosal infiltration of $\mathrm{CD}^{+}{ }^{+} \mathrm{T}$ cells as compared with mice treated with DMSO (Figure $7 \mathrm{e}$ and

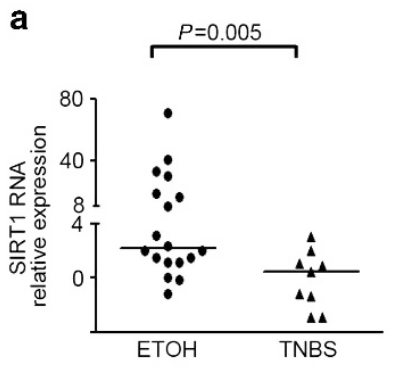

b
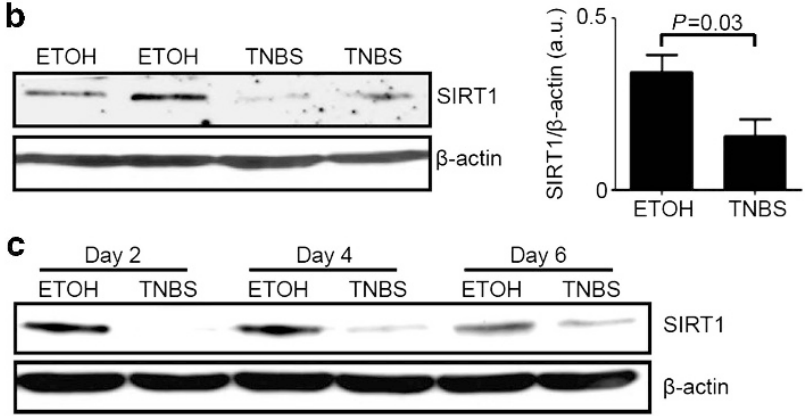

Figure 6 SIRT1 transcripts are downregulated in TNBS-induced colitis. (a) SIRT1 RNA expression was evaluated in colonic samples taken from 10 control mice $(\mathrm{ETOH})$ and 9 TNBS-treated mice (TNBS) by real-time PCR. Levels were normalized to $\beta$-actin and each point represents the value of SIRT1 RNA relative expression in colonic samples taken from a single mouse. (b) Representative western blots showing SIRT1 and $\beta$-actin in total proteins extracted from colonic samples of two control mice (ETOH) and two TNBS-treated mice (TNBS). Right panel shows the quantitative analysis of SIRT1/ 3 actin ratio in colonic samples taken from nine ETOH and five TNBS-treated mice as measured by densitometry scanning of western blots. Values are expressed in arbitrary units (a.u.) and indicate mean \pm s.e.m. of all the samples. (c) Representative western blots showing SIRT1 and $\beta$-actin in total proteins extracted from colonic samples of one control mouse (ETOH) and one TNBS-treated mouse (TNBS) at day 2, 4, and 6 after colitis induction, respectively. One of three independent experiments in which similar results were obtained is shown. ETOH, ethanol; TNBS, 2,4,6-trinitrobenzenesulphonic acid.

Figure 7 Cay10591 prevents/ameliorates and Ex527 exacerbates TNBS-induced colitis. (a) LPMC were isolated from TNBS-treated mice and preincubated with Cay10591 (CAY, $10 \mu \mathrm{M}$ ) or dimethyl sulfoxide (DMSO, vehicle) for $1 \mathrm{~h}$, and then either cultured with activating anti-CD3/CD28 antibodycoated beads or LPS $\left(100 \mathrm{ng} \mathrm{ml}^{-1}\right)$ for further $6 \mathrm{~h}$. RNA was extracted and amplified by real-time PCR. Levels are normalized to $\beta$-actin and indicate the mean \pm s.e.m. of all the experiments. Cay10591 (CAY) or DMSO was given orally the day before the induction of TNBS-colitis. (b) Photomicrograph $(\times 40)$ of an HE-stained paraffin section of representative colonic sections from mice belonging to each group. Severe mucosal mononuclear cell infiltrate and disruption of the normal crypt architecture with epithelial ulceration and loss of goblet cells is evident in the colon of TNBS-treated mice receiving DMSO. In contrast, only a minimal cellular infiltration of the mucosa is seen in the colon of mice treated with CAY. The photomicrographs are representative of two separate experiments in which at least six mice per group were studied. Right inset shows histological score of the colon sections taken from control (ETOH) and colitic mice either treated with or without CAY. Data indicate mean \pm s.e.m. of all the experiments. (c) Giving CAY to mice with TNBS-colitis results in decreased tissue expression of IFN- $\gamma$. Data indicate \pm s.e.m. of all the experiments. CAY or DMSO was administrated via oral gavage the day after the induction of TNBS-colitis. (d) Photomicrograph $(\times 40)$ of an HE-stained paraffin section of representative colonic sections from mice belonging to each group. Severe mucosal mononuclear cell infiltrate and disruption of the normal crypt architecture with epithelial ulceration and loss of goblet cells is evident in the colon of TNBS-treated mice receiving DMSO. In contrast, only a minimal cellular infiltration of the mucosa is seen in the colon of mice treated with CAY. The photomicrographs are representative of two separate experiments in which at least six mice per group were studied. Right inset shows histological score of the colon sections taken from control (ETOH) and colitic mice either treated with or without CAY. Data indicate mean \pm s.e.m. of all the experiments. (e) CAY treatment in colitic mice results in decreased tissue expression of IFN- $\gamma$. Data indicate \pm s.e.m. of all the experiments. EX527 or DMSO was orally administrated the day before the induction of a mild TNBS-colitis. (f) Photomicrograph ( $\times 40)$ of an HE-stained paraffin section of representative colonic sections from mice belonging to each group. Mild cellular infiltration of mucosa is seen in the colon of TNBStreated mice receiving DMSO. In contrast, severe mucosal mononuclear cell infiltrate and disruption of the normal crypt architecture with epithelial ulceration and loss of goblet cells is evident in the colon of TNBS-treated mice receiving EX527. The photomicrographs are representative of two separate experiments in which at least six mice per group were studied. Right inset shows histological score of the colon sections taken from control (ETOH) and colitic mice either treated with or without EX527. Data indicate mean \pm s.e.m. of all the experiments. (g) Giving EX527 to mice with TNBS-colitis results in enhanced tissue expression of IFN- $\gamma$. Data indicate \pm s.e.m. of all the experiments. ETOH, ethanol; HE, hematoxylin and eosin; IFN, interferon; LPMC, lamina propria mononuclear cell; TNBS, 2,4,6-trinitrobenzenesulphonic acid. 
Supplementary Figure 2B, left panel). In contrast, no significant change in the colonic infiltration of $\mathrm{F} 4 / 80^{+}$cells was seen following Cay10591 treatment (Supplementary Figure 2B, right panel).

Next, mice were given Ex527 the day before the induction of TNBS-colitis. For these experiments, a smaller amount of TNBS (1 mg) was administered to induce a milder colitis. As shown in Figures 7f and g, Ex527-treated mice exhibited a more severe colitis than control mice associated with greater production of IFN- $\gamma$ in the colon. These observations were associated with enhanced colonic infiltration of $\mathrm{CD}^{+} \mathrm{T}$ cells but not of $\mathrm{F} 4 / 80^{+}$cells in TNBS-treated mice receiving Ex527 as compared with those given DMSO (Supplementary Figure 2C).

\section{Cay10591 ameliorates oxazolone-induced colitis}

As SIRT1 activation leads to reduced expression of inflammatory cytokines in UC LPMC, we finally evaluated whether
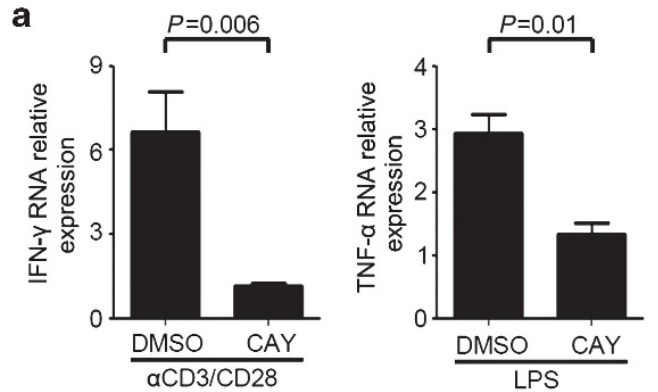

b
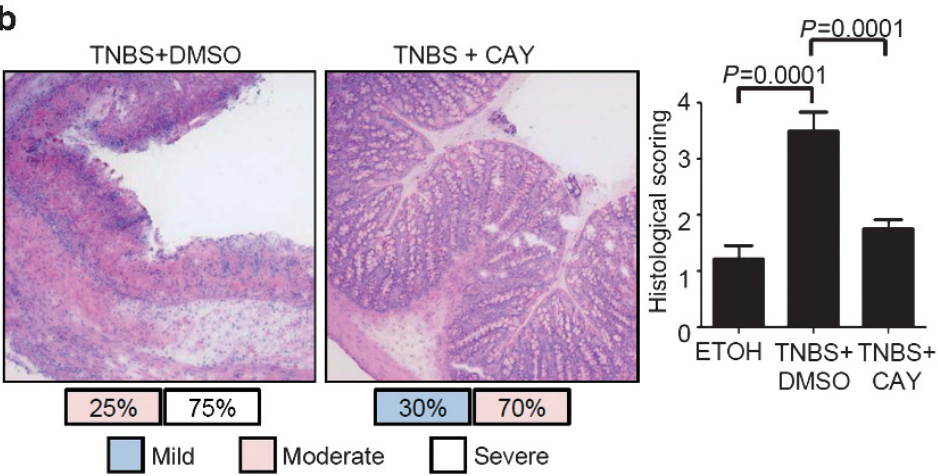

d
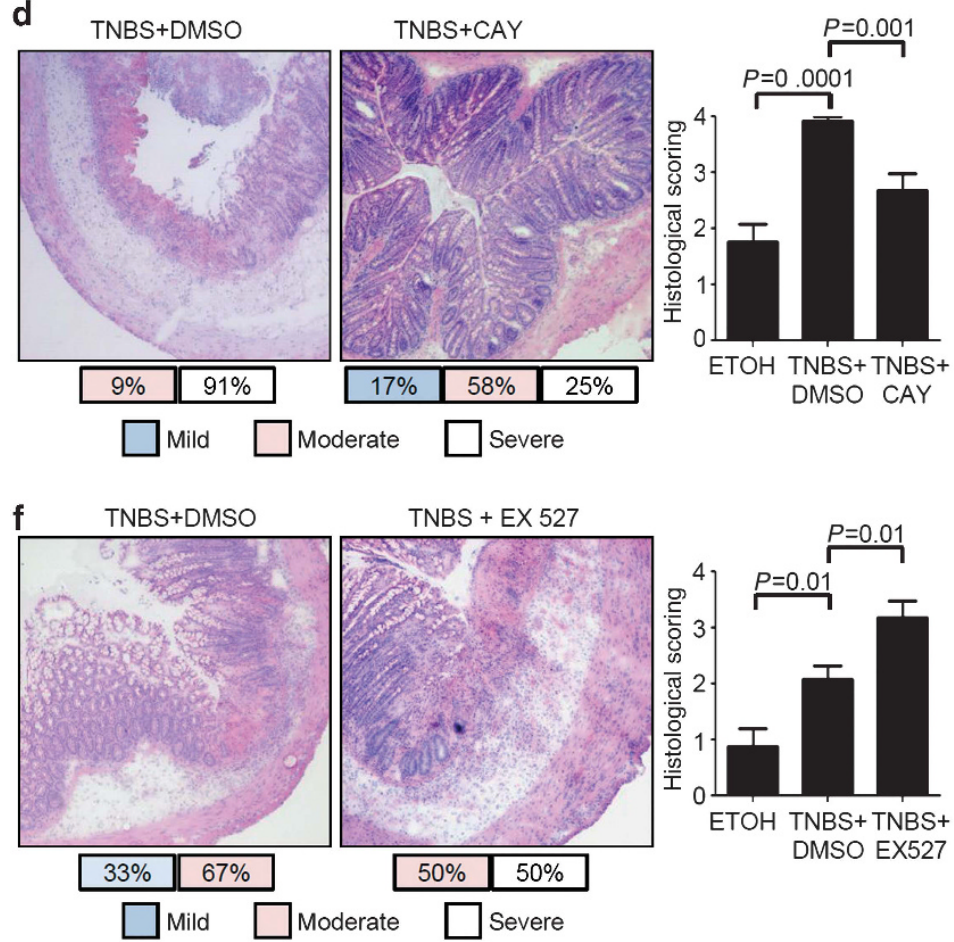

c
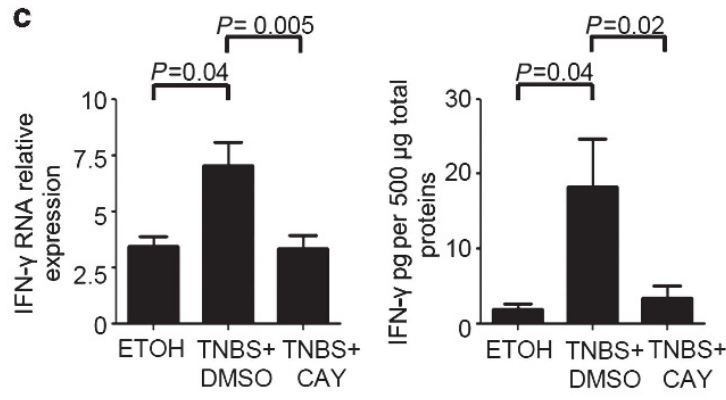

e
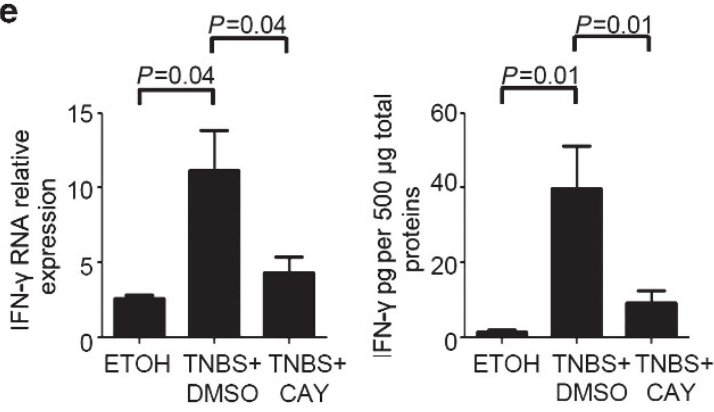

g
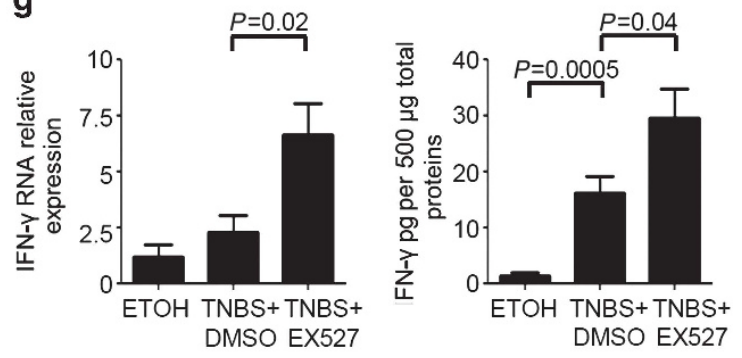


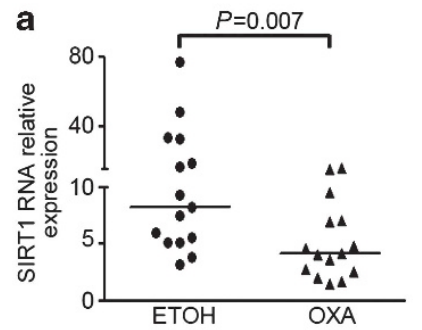

b
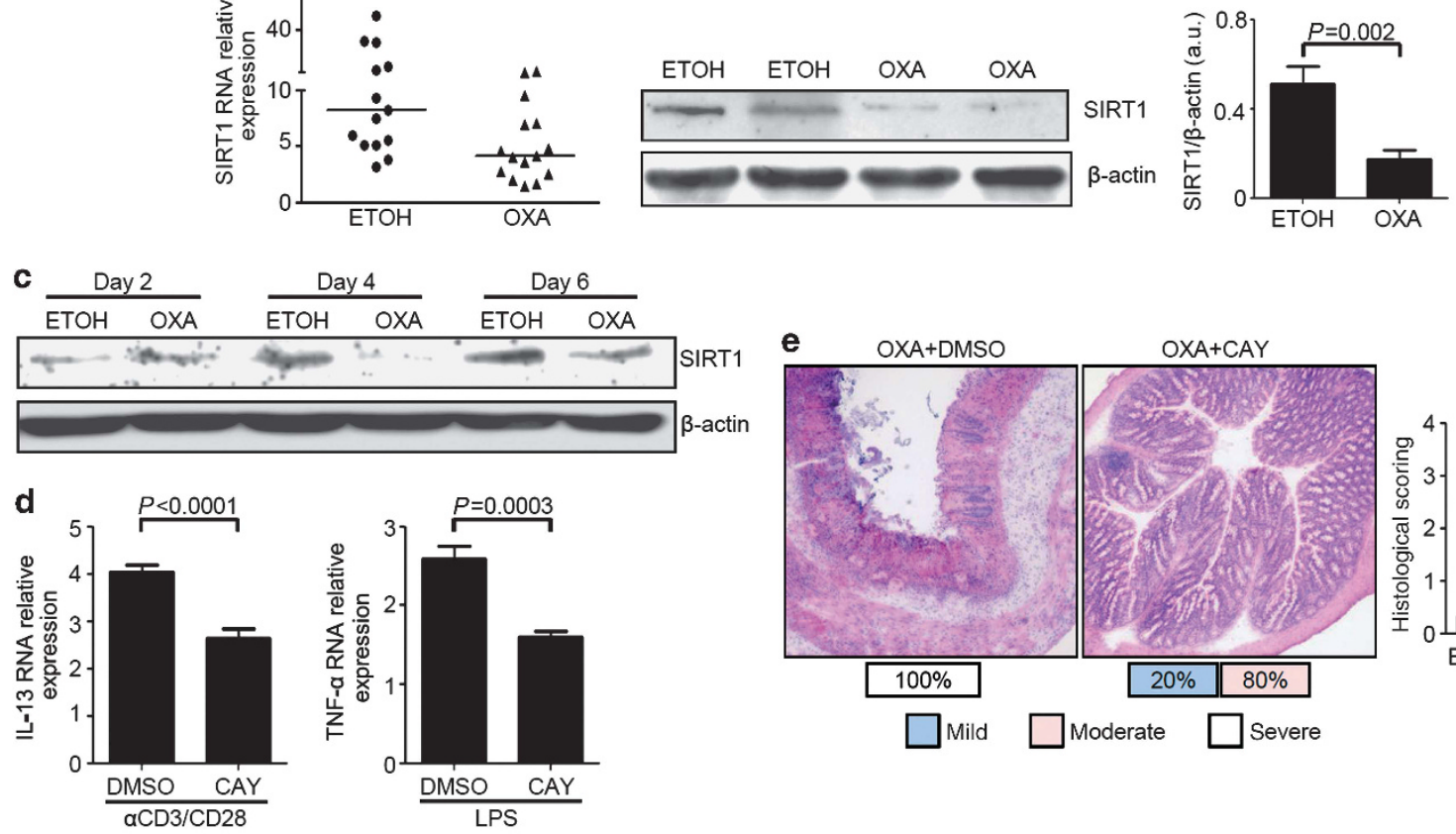

Day 4

Day 6

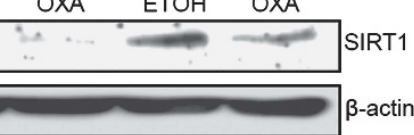

e
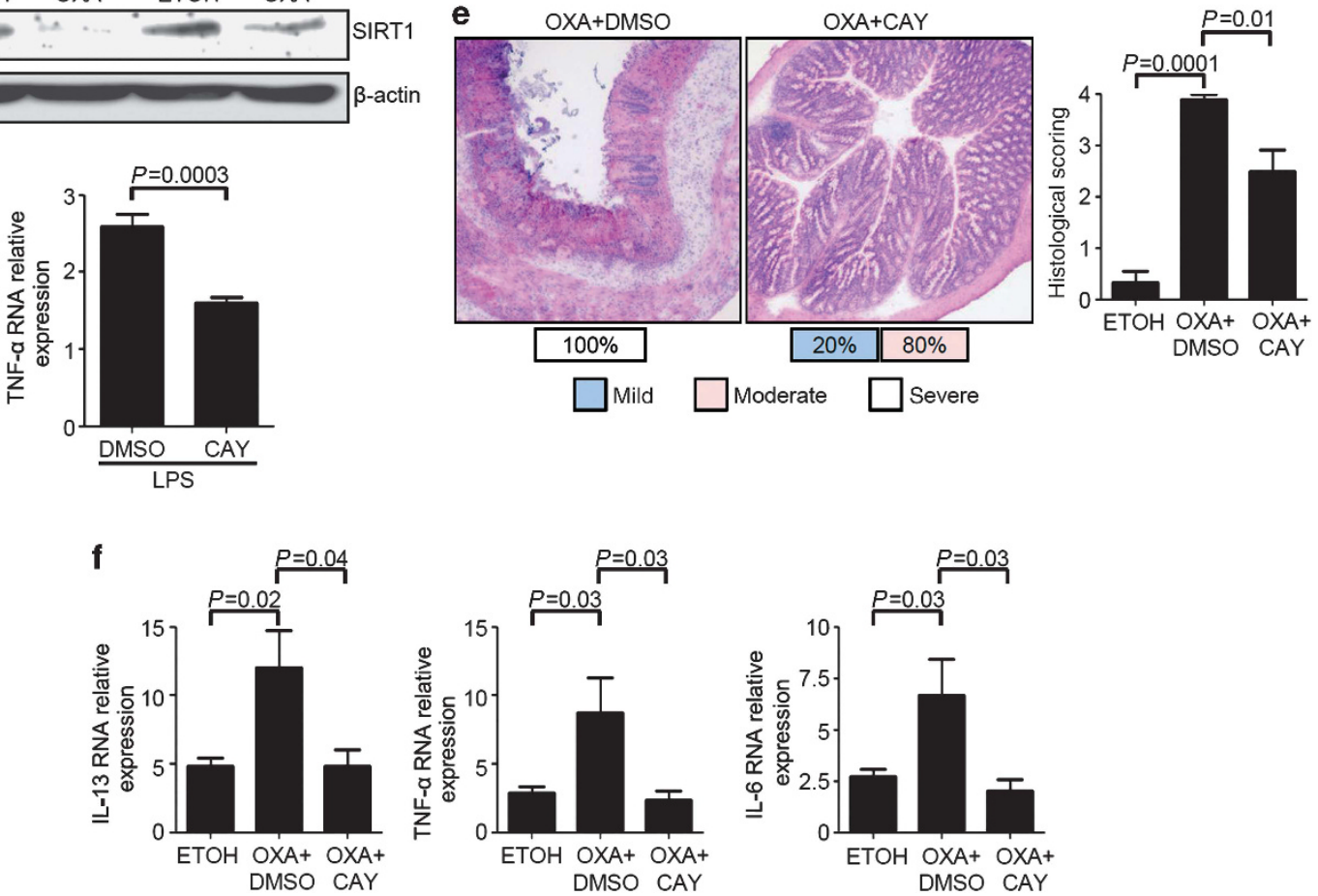

Figure 8 Cay 10591 ameliorates oxazolone-induced colitis. (a) SIRT1 RNA expression was evaluated in colonic samples taken from 15 control mice (ETOH) and 14 oxazolone-treated mice (OXA) by real-time PCR. Levels were normalized to $\beta$-actin and each point represents the value of SIRT1 RNA relative expression in colonic samples taken from a single mouse. (b) Representative western blots showing SIRT1 and $\beta$-actin in total proteins extracted from colonic samples of two control mice $(\mathrm{ETOH})$ and two oxazolone-treated mice $(\mathrm{OXA})$. Right panel shows the quantitative analysis of SIRT1/ $\beta$-actin ratio in colonic samples taken from nine $\mathrm{ETOH}$ and seven oxazolone-treated mice as measured by densitometry scanning of western blots. Values are expressed in arbitrary units (a.u.) and indicate mean \pm s.e.m. of all the samples. (c) Representative western blots showing SIRT1 and $\beta$-actin in total proteins extracted from the colonic samples of one control mouse (ETOH) and one oxazolone-treated mouse (OXA) at days 2, 4, and 6. One of three independent experiments in which similar results were obtained is shown. Cay10591 prevents oxazolone-induced colitis. (d) LPMC were isolated from oxazolone-treated mice and pre-incubated with Cay10591 (CAY, $10 \mu \mathrm{M}$ ) or dimethyl sulfoxide (DMSO, vehicle) for $1 \mathrm{~h}$, and then either cultured with activating anti-CD3/CD28 antibody-coated beads or LPS $\left(100 \mathrm{ng} \mathrm{ml}^{-1}\right)$ for further $6 \mathrm{~h}$. RNA was extracted and amplified by real-time PCR. Levels are normalized to $\beta$-actin and indicate the mean \pm s.e.m. of all the experiments. Cay10591 (CAY) or DMSO was orally administrated the day before the induction of oxazolone-colitis. (e) Photomicrograph $(\times 40)$ of an HE-stained paraffin section of representative colonic sections from mice belonging to each group. Severe mononuclear cell infiltrate involving the whole colonic wall, with disruption of the normal crypt architecture and loss of goblet cells is evident in the colon of oxazolone-treated mice receiving DMSO. In contrast, only a minimal cellular infiltration of the mucosa is seen in the colon of mice treated with CAY. The photomicrographs are representative of two separate experiments in which at least six mice per group were studied. Right inset shows histological score of the colon sections taken from control (ETOH) and colitic mice either treated with or without CAY. Data indicate mean \pm s.e.m. of all the experiments. (f) Giving CAY to mice with oxazolone-colitis results in decreased tissue expression of IL-13, TNF- $\alpha$, and IL-6. Data indicate \pm s.e.m. of all the experiments. ETOH, ethanol; HE, hematoxylin and eosin; IL, interleukin; LPMC, lamina propria mononuclear cell; OXA, oxazolone; TNF, tumor necrosis factor.

Cay10591 was also effective in attenuating inflammation in mice with the UC-like oxazolone-colitis. ${ }^{23}$ Initially, we showed that induction of oxazolone-colitis was accompanied by a significant downregulation of SIRT1 RNA and protein expression in the colons of mice (Figures 8a and $\mathbf{b}$ ). Timecourse experiments in oxazolone-treated mice showed that downregulation of SIRT1 was evident at day 4 but not at earlier time points (i.e., day 2) (Figure 8c). Treatment of LPMC isolated from oxazolone-treated mice with Cay10591 decreased both anti-CD3/CD28-driven IL-13 and LPS-driven TNF- $\alpha$ expression (Figure 8d).

Finally, Cay10591 (or DMSO) was administered to mice the day before oxazolone-colitis induction. Histopathological appearance of the bowel wall of mice revealed that oxazolone-colitis was 
less severe in Cay10591-treated mice and this was associated with a significant downregulation of IL-13, TNF- $\alpha$, and IL-6 (Figures $8 \mathbf{e}$ and $\mathbf{f}$ ), which are known to drive the pathological immune response in this model. ${ }^{24,25}$ The number of $\mathrm{CD}^{+} \mathrm{T}$ cells, but not of $\mathrm{F} 4 / 80^{+}$cells, infiltrating the colon of oxazolone-treated mice was significantly reduced by Cay10591 (Supplementary Figure 3).

\section{DISCUSSION}

In this study we investigated the expression and role of SIRT1 in the gut of IBD patients and in mice with experimental colitis. SIRT1-deficient mice demonstrate lack of tissue and systemic immune regulation and are more prone to develop inflammation in many organs. ${ }^{12}$ Moreover, SIRT1-deficient T cells and macrophages are hyperactivated and produce large amounts of inflammatory cytokines, highlighting the role of SIRT1 in the negative control of immune-inflammatory pathways. ${ }^{12,14}$ Here we observed a significant decrease in SIRT1 RNA expression in both $\mathrm{CD}$ and UC compared with controls. Western blotting and flow cytometry analysis confirmed the downregulation of SIRT1 protein in IBD, particularly in mononuclear cells in the lamina propria. Flow cytometry analysis also revealed a reduced expression of SIRT1 protein in blood mononuclear cells of IBD patients compared with controls. The reason why SIRT1 is downregulated in circulating $\mathrm{CD}^{+}, \mathrm{CD}_{1} 9^{+}$, and HLA-DR ${ }^{+}$ cells of IBD patients is unknown even though it is conceivable that this finding can reflect a preferential migration of SIRT1expressing cells from blood to inflamed gut of CD patients and UC patients. SIRT1 can be regulated at transcriptional, posttranscriptional, and posttranslational levels by multiple factors, which can either enhance or suppress its expression and function. ${ }^{26}$ The present study was also designed to determine factors involved in SIRT1 regulation in the human gut. Our data indicate that, in IBD, the decreased intestinal expression of SIRT1 was restricted to mucosal areas with active inflammation. In addition, the expression of SIRT1 in samples taken from uninflamed mucosa of IBD patients did not differ from that seen in the colon of controls and there was no difference in SIRT1 expression between IBD patients taking no therapy and those who were receiving drugs. Although we have very little understanding of the control of SIRT1 in the human gut, our findings suggest that cytokines overproduced in the inflamed tissue of IBD patients may contribute to downregulate SIRT1 expression. Indeed, stimulation of control LPMC with TNF- $\alpha$ and IL-21 reduced SIRT1 expression, and treatment of IBD LPMC with IFX or with a neutralizing anti-IL-21 antibody enhanced SIRT1 protein expression.

These findings are consistent with reduced expression of SIRT1 in the colon of patients with diverticular disease, as it has been previously reported that TNF- $\alpha$ is highly synthesized in this disorder. ${ }^{27}$ In contrast, SIRT1 was not downregulated in the duodenum of patients with active celiac disease, a pathologic condition associated with no induction of TNF- $\alpha .{ }^{28}$

Our findings support and expand on previous studies showing a significant reduction of SIRT1 in other inflammatory disorders, such as chronic obstructive pulmonary disease. ${ }^{29}$ In this context, it is also noteworthy that a mutation in the SIRT1 gene has recently been associated with the development of type 1 diabetes in four members of a single family, with another sibling developing UC. ${ }^{30}$

To assess the function of SIRT1 in the gut, we used two commercial compounds, which have the ability to selectively and specifically activate (i.e., Cay10591) or inhibit (i.e., Ex527) SIRT1. Both compounds, which were identified through a highthroughput screen against human recombinant SIRT1, display a high degree of selectivity for SIRT1 and do not target class I and II HDACs nor NAD glycohydrolase. ${ }^{31,32}$ In line with previous observations showing that SIRT1 modulates the acetylation status of NF- $\kappa B p 65$ and inhibits NF- $\kappa \mathrm{B}$-mediated transcription, ${ }^{14,33}$ our data show that treatment with Cay10591 deacetylated NF-кBp65 and promoted its ubiquitination, thereby reducing NF- $\kappa B p 65$ activation in IBD LPMC. Consistently, treatment of CD and UC LPMC with Cay10591 significantly reduced IFN- $\gamma$, IL-17A, and IL-21 expression, thus confirming previous studies showing a key role of SIRT1 in suppressing the differentiation and effector function of Th1 and Th17 cells. ${ }^{12,34}$ Moreover, treatment of UC LPMC with Cay10591 markedly inhibited IL-17A, IL-21, and IL-13. These later data could appear surprising as IL-13 is synthesized prevalently during Th2 cell responses, ${ }^{17,21}$ and inhibition of Th1 cell differentiation by SIRT1 should promote rather than inhibit Th2 cytokines. However, it has been reported that when stimulated with anti-CD3/CD28 in vitro, SIRT1-deficient T cells produce more IL-5, another Th2-type cytokine, as compared with SIRT1-expressing T cells. ${ }^{12}$ Thus, it is plausible that SIRT1 exerts a broad negative effect on immune cell-derived inflammatory cytokine production rather than selectively suppressing the synthesis of Th1/Th17-related molecules.

To translate our data in vivo, we used two different models of colitis (i.e., TNBS- and oxazolone-colitis) and showed that SIRT1 expression was downregulated in the colon of colitic mice. Moreover, either activation or inhibition of SIRT1 with Cay10591 or Ex527 in vivo in mice attenuated or aggravated the intestinal inflammation, respectively. These results confirm earlier findings that SIRT1 content is reduced in the colon of mice with DSS (dextran sodium sulfate)-induced colitis and the polyphenolic phytoalexin, resveratrol, restores SIRT1 levels in the colon, reverses DSS colitis, and reduces the number of activated $\mathrm{T}$ cells in both mesenteric lymph node and lamina propria. ${ }^{35}$ However these data are rather difficult to interpret because resveratrol exerts anti-inflammatory effects via other mechanisms in addition to SIRT1 activation. ${ }^{36,37}$ Our data also indicated that Cay10591 treatment led to a significant reduction of LPS-induced TNF- $\alpha$ production in cultures of LPMC isolated from the colons of both TNBS- and oxazolonetreated mice. However, we did not observe any changes in the number of mucosal $\mathrm{F} 4 / 80^{+}$macrophages in TNBS- or oxazolone-treated mice either receiving Cay10591 or Ex527 compared with DMSO, thus suggesting that SIRT1 mostly affects the activation rather than the survival of intestinal macrophages. 
The mechanism by which Cay10591 suppresses inflammatory signals in the gut remains to be ascertained, but our in vitro observations indicate that SIRT1 deacetylates and promotes degradation of NF- $\kappa B p 65$, whose expression/function facilitates production of inflammatory cytokines in T cells. ${ }^{38}$ So it is plausible that the in vivo anti-inflammatory effects of Cay10591 may rely on its ability to regulate NF- $\kappa \mathrm{B}$-mediated transcription.

Our data are somehow conflicting with those recently published by Akimova et al. showing that inhibition of SIRT1 ameliorated disease severity and weight loss in both adoptive transfer colitis and cyclic DSS colitis by increasing regulatory $\mathrm{T}$ cells formation. ${ }^{39}$ We demonstrated that oral treatment with SIRT1 inhibitor (Ex527) exacerbated acute TNBS-induced colitis. Therefore, it is conceivable that this discrepancy may reflect differences in the experimental model of colitis as well as in the dose and route of administration of Ex527 used in these studies.

In conclusion, our study shows that SIRT1 expression is downregulated in the gut of IBD patients and mice with IBDlike colitis and activation of SIRT1 abrogates pro-inflammatory cytokine production and reduces intestinal damage in mice. Taken together these data suggest that SIRT1 activators might be useful as therapeutic reagents for the treatment of IBD.

\section{METHODS}

Patients and samples. Mucosal biopsies were taken from the inflamed areas of 6 patients with colonic $\mathrm{CD}, 15$ patients with ileocolonic $\mathrm{CD}, 7$ patients with ileal $\mathrm{CD}$, and 29 patients with UC undergoing colonoscopy for a clinically active disease at the Gastrointestinal Unit of Tor Vergata University (Rome, Italy) or Fondazione IRCCS CàGranda, Ospedale Maggiore Policlinico (Milan, Italy). Paired biopsies were also taken from the inflamed and uninflamed mucosa of two patients with ileocolonic CD and four patients with UC. Thirteen patients (two colonic $\mathrm{CD}$, three ileocolonic $\mathrm{CD}$, two ileal $\mathrm{CD}$, and six UC) were taking no drug and the biopsies were collected at the time of initial diagnosis. Twenty-four patients ( 2 colonic CD, 4 ileocolic CD, 2 ileal CD, and $16 \mathrm{UC}$ ) were receiving mesalamine, 15 patients ( 1 colonic $\mathrm{CD}, 1$ ileal CD, 4 ileocolonic $\mathrm{CD}$, and $9 \mathrm{UC}$ ) were taking steroids, 10 patients ( 1 colonic CD, 6 ileocolonic CD, 2 ileal CD and 1 UC) were on immunosuppressive drugs, and 1 UC patient was receiving both steroids and immunosuppressive drugs. In all these patients, endoscopy was performed for a clinical relapse of the disease and endoscopic activity was evaluated by means of simple endoscopic score for CD and Mayo endoscopic subscore. ${ }^{40,41}$ Nine steroid-dependent and/or resistant patients (three colonic $\mathrm{CD}$, two ileocolonic $\mathrm{CD}$, and four UC) were treated with IFX. Each patient received a total of three IFX infusions ( $5 \mathrm{mg} \mathrm{kg}^{-1}$ ) at week 0,2 , and 6 . Colonic biopsies were collected from the sigmoid colon before the first and after the third IFX infusion. Six patients (three colonic CD and three UC) were defined "responders", since they were in clinical remission and exhibited a complete mucosal healing following the last IFX infusion, whereas three patients (two ileocolonic CD and one UC) were defined "nonresponders", as neither clinical benefit nor mucosal healing were observed following the last IFX infusion. Endoscopic activity was evaluated as described above. ${ }^{40,41}$ Two UC patients were receiving azathioprine, one colonic $\mathrm{CD}$ patient was taking mesalamine and azathioprine, three patients (one colonic $\mathrm{CD}$, one ileocolonic $\mathrm{CD}$, and one UC) were treated with mesalamine only because they were intolerant to immunosuppressors, and one UC patient was receiving azathioprine and steroids. All the concomitant therapies were maintained during IFX treatment. Two patients (one ileocolonic CD and one colonic $\mathrm{CD}$ ) were taking no drugs during IFX treatment.
In addition, surgical specimens were taken from 11 patients with colonic $\mathrm{CD}$, and 14 patients with UC undergoing surgery for a chronic active disease poorly responsive to medical treatment, and from 9 patients with ileal CD undergoing surgery due to a stricturing disease.

Controls included biopsies taken from unaffected colonic mucosa of 21 subjects and unaffected ileal mucosa of 5 subjects undergoing colonoscopy for colorectal cancer screening. Additional controls were mucosal specimens taken from macroscopically and microscopically unaffected colonic areas of 21 patients undergoing surgery for colon cancer and from 4 patients with diverticular disease undergoing surgery for diverticulitis. Further controls included duodenal mucosal samples taken from nine patients on a gluten-containing diet. All these patients were positive for both serum anti-endomysium IgA antibody and anti-tissue transglutaminase- 2 antibody and had villous atrophy on the histological examination according to Marsh classification (grade III A-C). ${ }^{42}$ An additional control group included duodenal mucosal samples taken from eight individuals who were negative for both antibodies while receiving a gluten-containing diet and had no villous atrophy (Marsh 0 ).

Autologous peripheral blood samples were obtained from two UC patients (both receiving steroids), one ileal CD patient who was taking mesalamine, two ileocolonic CD patients (one patient was receiving steroids and one patient was taking mesalamine), and three controls (CTR). Clinical characteristic of IBD patients and controls are shown in Table 1.

Informed consent was obtained from all the patients and the study protocol was approved by the local ethics committees.

RNA extraction, cDNA preparation and real-time PCR. Total RNA was extracted using Pure Link mRNA mini kit according to the manufacturer's instructions (Life Technologies, Milan, Italy). A constant amount of RNA ( $1 \mu$ g per sample) was retro-transcribed into complementary DNA (cDNA) and then $1 \mu \mathrm{l}$ of cDNA per sample was amplified using a SYBER Green master mix (Bio-Rad, Milan, Italy). PCR was performed using the following conditions: denaturation $1 \mathrm{~min}$ at $95^{\circ} \mathrm{C}$; annealing $30 \mathrm{~s}$ at $58^{\circ} \mathrm{C}$ for hSIRT1, hSIRT2, hIFN- $\gamma$, hIL-21, mTNF- $\alpha$, mIL- 13 , and mIL- 6 ; at $60^{\circ} \mathrm{C}$ for $\beta$-actin and mIFN$\gamma$; and at $61^{\circ} \mathrm{C}$ for hIL-17A and mSIRT1; followed by $30 \mathrm{~s}$ of extension at $72{ }^{\circ} \mathrm{C}$. Primers sequence was as follows: hSIRT1 forward $5^{\prime}$-ACAT AGACACGCTGGAACAG-3' , reverse $5^{\prime}$-TAGGACATCGAGGAA CTACC- $3^{\prime}$; hSIRT2 forward $5^{\prime}$-CCTTCTACACATCACACTGC- $3^{\prime}$, reverse $5^{\prime}$-GGCTCTCACCAAAAAAGACG-3'; hIFN- $\gamma$ forward $5^{\prime}$ TGGAGACCATCAAGGAAGAC- $3^{\prime}$; reverse $5^{\prime}$-GCGTTGGACATT CAAGTCAG-3'; hIL-21 forward 5'-GGAGAGGATTGTCATCT GTC- $3^{\prime}$, reverse $5^{\prime}$-CACAGTTTGTCTCTACATCTTC- $3^{\prime}$; mTNF- $\alpha$ forward $5^{\prime}$-ACCCTCACACTCAGATCATC- $3^{\prime}$, reverse $5^{\prime}$-GAGTAGACAAGGTACAACCC-3'; mIL-13 forward 5'-GAGCAACA TCACACAAGACC- $3^{\prime}$, reverse $5^{\prime}$-AATCCAGGGCTACACAGAAC3'; mIL-6 forward $5^{\prime}$-AGCCAGAGTCCTTCAGAGAG-3', reverse $5^{\prime}$ GATGGTCTTGGTCCTTAGCC- $3^{\prime}$; mIFN- $\gamma$ forward $5^{\prime}$-CAATGA ACGCTACACACTGC- $3^{\prime}$, reverse $5^{\prime}$-CCACATCTATGCCACTTG AG-3'; hIL-17A forward 5'-ACTACAACCGATCCACCTCAC-3', reverse $5^{\prime}$-ACTTTGCCTCCCAGATCACAG-3'; mSIRT1 forward $5^{\prime}$ CTTTCAGAACCACCAAAGCGG-3', reverse $5^{\prime}$-GCAAGGCGAGC ATAGATACC- $3^{\prime}$; $\beta$-actin forward $5^{\prime}$-AAGATGACCCAGATCATG TTTGAGACC- $3^{\prime}, \quad$ reverse $5^{\prime}$-AGCCAGTCCAGACGCAGGA $\mathrm{T}-3^{\prime}$ was used as internal control.

RNA expression was calculated relative to the housekeeping $\beta$-actin gene on the base of the $\Delta \Delta \mathrm{Ct}$ algorithm.

Total protein extraction and western blotting. Intestinal mucosal samples and LPMC of control patients, UC patients, and CD patients and colonic samples of mice with colitis induced by TNBS or oxazolone or treated with ethanol were lysed on ice with a buffer containing 10 mM HEPES (pH 7.9), $10 \mathrm{~mm} \mathrm{KCl,} 0.1 \mathrm{~mm}$ EDTA, and 0.5\% Nonidet p40, supplemented with $1 \mathrm{~mm}$ dithiothreitol, $10 \mathrm{mg} \mathrm{ml}^{-1}$ aprotinin, $10 \mathrm{mg} \mathrm{ml}^{-1}$ leupeptin, $1 \mathrm{~mm}$ phenyl-methylsulfonyl fluoride, $1 \mathrm{~mm}$ $\mathrm{Na}_{3} \mathrm{VO}_{4}$, and $1 \mathrm{~mm} \mathrm{NaF}$. Lysates were clarified by centrifugation at 
Table 1 Clinical characteristic of Crohn's disease patients, ulcerative colitis patients, and controls

\begin{tabular}{lcll}
\hline & CD, $\mathbf{N}=\mathbf{5 8}$ & UC, $\boldsymbol{N}=\mathbf{5 3}$ & CTR, $\boldsymbol{N}=71$ \\
\hline Gender, male: n (\%) & $26(44.8)$ & $30(56.6)$ & $29(40.8)$ \\
Age: median (range) & $32.5(20-78)$ & $48(20-81)$ & $41(18-78)$ \\
& & & \\
CD location: n (\%) & & \\
Terminal ileum & $13(22.4)$ & \\
Pre-anastomotic ileum & $4(6.9)$ & \\
lleo-colon & $21(36.2)$ & \\
Colon & $20(34.5)$ &
\end{tabular}

UC extent: $\mathrm{n}(\%)$

Proctitis

$13(24.5)$

Left-side colitis

$12(22.7)$

Extensive colitis

$28(52.8)$

Indication for evaluation: n (\%)

Symptom onset/initial diagnosis of IBD

Clinical relapse of disease

Chronic active disease

Stricturing disease

CRC screening

Diverticular disease

CRC surgery

Symptoms/signs suggestive of celiac disease

First-degree family member with celiac disease

Voluntary blood donor

$\begin{array}{ccc}7(12.1) & 6(11.3) & 0 \\ 31(53.4) & 33(62.3) & 0 \\ 11(19.0) & 14(26.4) & 0 \\ 9(15.5) & 0 & 0 \\ 0 & 0 & 26(36.6) \\ 0 & 0 & 4(5.6) \\ 0 & 0 & 21(29.6) \\ 0 & 0 & 11(15.5) \\ 0 & 0 & 6(8.5) \\ 0 & 0 & 3(4.2)\end{array}$

Sampling site: $\mathrm{n}$ (\%)

Duodenum

Terminal ileum

Pre-anastomotic ileum

Colon

Peripheral blood

\section{Current therapy: $\mathrm{n}(\%)$}

\begin{tabular}{lccc} 
None & $7(12.1)$ & $6(11.3)$ & $71(100)$ \\
Systemic CS & $24(41.3)$ & $25(47.1)$ & 0 \\
Budesonide & $2(3.5)$ & 0 & 0 \\
Mesalamine & $10(17.2)$ & $16(30.2)$ & 0 \\
ISS & $10(17.2)$ & $1(1.9)$ & 0 \\
Anti-TNF & $2(3.5)$ & 0 & 0 \\
Systemic CS + ISS & 0 & $1(1.9)$ & 0 \\
Systemic CS + Anti-TNF & 0 & $1(1.9)$ & 0 \\
Mesalamine + Anti-TNF & $2(3.5)$ & $1(1.9)$ & 0 \\
ISS + Anti-TNF & $1(1.7)$ & $2(3.8)$ & 0 \\
\hline
\end{tabular}

CD, Crohn's disease; CRC, colorectal cancer; CS, corticosteroids; CTR, controls; IBD, inflammatory bowel disease; ISS, immunosuppressive drugs; TNF, tumor necrosis factor; UC, ulcerative colitis.

$12,000 \mathrm{~g}$ for $30 \mathrm{~min}$ at $4{ }^{\circ} \mathrm{C}$ and separated on $8 \%$ or $10 \%$ SDSpolyacrylamide gel electrophoresis to assess human/mouse SIRT1 or NF-אBp65, respectively. Human SIRT1 was detected using a monoclonal mouse anti-human antibody (final concentration $0.5 \mu \mathrm{g} \mathrm{ml}^{-1}$, Millipore, Milan, Italy) followed by a horseradish peroxidase-conjugated rabbit anti-mouse IgG monoclonal antibody (Dako, Milan, Italy). Mouse SIRT1 was detected using a monoclonal rabbit anti-mouse antibody (final dilution 1:300, Biorbyt, Milan, Italy) followed by a horseradish peroxidase-conjugated goat anti-rabbit IgG monoclonal antibody (Dako). NF-אBp65 was detected using a polyclonal rabbit anti-human antibody (final dilution 1:500, Santa Cruz Biotechnology, Santa Cruz, CA) followed by a horseradish peroxidase-conjugated goat anti-rabbit IgG monoclonal antibody (Dako). The reactions were detected with a sensitive enhanced chemiluminescence kit (Pierce, Rockford, IL). After the analysis, blots were stripped and incubated with a mouse anti-human $\beta$-actin antibody (Sigma-Aldrich, Milan, Italy) as internal loading control, followed by a rabbit anti-mouse antibody conjugated to horseradish peroxidase to ascertain equivalent loading of lanes.

Immunoprecipitation. For immunoprecipitation, the protein lysates were prepared from cells pre-incubated with Cay10591 $(10 \mu \mathrm{M}$, Cayman Chemical, Montigny-le-Bretonneux, France) or DMSO (vehicle) for $1 \mathrm{~h}$ and then stimulated with activating anti-CD3/CD28 antibody-coated beads (Miltenyi Biotec, Bergish Gladbach, Germany) for $16 \mathrm{~h}$. Proteins were immunoprecipitated with $2 \mu \mathrm{g}$ of anti-NF$\kappa B p 65$ (Santa Cruz Biotechnology) or control isotype antiserum for $2 \mathrm{~h}$ followed by incubation with protein $\mathrm{A} / \mathrm{G}$ agarose beads overnight. The resulting immunoprecipitates were washed thoroughly four times with cold lysis buffer, separated by SDS-polyacrylamide gel electrophoresis and immunoblotted with antibodies against acetyl-lysine (final concentration $0.5 \mu \mathrm{g} \mathrm{ml}^{-1}$, Millipore).At the end, blots were stripped and incubated with anti-ubiquitin antibody (final dilution 1:500, Santa Cruz Biotechnology).

NF- $\kappa$ B activation assay. The NF- $\kappa B$ activity was quantified using an ELISA(enzyme-linked immunosorbent assay)-based TransAM NF$\kappa \mathrm{B}$ p65 kit (Active Motif, La Hulpe, Belgium) according to the manufacturer's protocol.

Peripheral blood mononuclear cells and LPMCs isolation and cell sorting. All reagents were from Sigma-Aldrich unless specified. Human peripheral blood mononuclear cells (PBMC) were isolated from EDTA-stabilized blood samples of CTR and IBD patients by Ficoll gradients. LPMC were isolated from mucosal specimens as previously described. ${ }^{43}$ PBMC and LPMC were used to sequentially purify $\mathrm{CD}^{+}{ }^{+}$cells, $\mathrm{CD} 19^{+}$cells, and $\mathrm{HLA}-\mathrm{DR}{ }^{+}$cells using magnetic beads (Miltenyi Biotec). Cell purity was routinely evaluated by flow cytometry and ranged between 94 and 98\%. The purified cells were used to assess SIRT1 by flow cytometry. An aliquot of LPMC was used to assess SIRT1 protein expression by western blotting whereas the remaining LPMC were re-suspended in X-Vivo supplemented with penicillin $\left(100 \mu \mathrm{g} \mathrm{ml}^{-1}\right)$, streptomycin $\left(100 \mu \mathrm{g} \mathrm{ml}^{-1}\right)$, and gentamycin $\left(50 \mu \mathrm{g} \mathrm{ml}^{-1}\right.$, Lonza, Verviers,

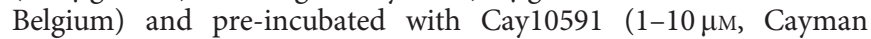
Chemical), Ex527 (50-100 $\mu \mathrm{M}$, Tocris, Bristol, UK) or DMSO (vehicle) for $1 \mathrm{~h}$ and then stimulated with activating anti-CD3/CD28 antibodycoated beads (Miltenyi Biotec) for 6-16 h. In parallel experiments, LPMC were incubated with Cay10591 (1-10 $\mu \mathrm{M}$, Cayman Chemical), Ex527 (50-100 $\mathrm{M}$, Tocris) or DMSO (vehicle) for $19 \mathrm{~h}$ and then stimulated with Phorbol 12-myristate 13-acetate $\left(40 \mathrm{ng} \mathrm{ml}^{-1}\right)$, ionomycin $\left(1 \mu \mathrm{g} \mathrm{ml}^{-1}\right)$, and monensin $\left(2 \mu \mathrm{moll}^{-1}\right.$, from eBioscience, San Diego, CA) for further $5 \mathrm{~h}$ and analyzed by flow cytometry. To evaluate whether inflammatory stimuli inhibit SIRT1 expression, control LPMC were either left unstimulated or stimulated with TNF- $\alpha$ (20 ng ml ${ }^{-1}, \quad$ R\&D Systems, Minneapolis, MN), IL-21 $\left(50 \mu \mathrm{g} \mathrm{ml}^{-1}\right.$, BioSource International, Camarillo, CA), IFN- $\gamma$ (100 $\mathrm{n} \mathrm{ml}^{-1}$, PeproTech, London, UK) or IL-17A $\left(20 \mathrm{ng} \mathrm{ml}^{-1}\right.$, PeproTech) for 6-24h. Moreover, IBD LPMC were incubated with a neutralizing IL-21 antibody $\left(10 \mu \mathrm{g} \mathrm{ml}^{-1}\right),{ }^{44}$ IFX or control human IgG (both at $50 \mu \mathrm{g} \mathrm{ml}^{-1}$ ) for $48 \mathrm{~h}$. Cells were then used to assess SIRT1 
RNA and protein expression by real-time PCR and western blotting, respectively.

Flow cytometry analysis. Purified $\mathrm{CD}^{+}, \mathrm{CD} 19^{+}$, and HLA-DR ${ }^{+}$ cells were fixed with $4 \%$ paraformaldehyde for $15 \mathrm{~min}$ at room temperature and then subjected to heat-induced antigen retrieval in citrate buffer $(\mathrm{pH} \mathrm{6.0)}$ for 2 min. Once permeabilized with Triton $\left(0.5 \%\right.$, Bio-Rad) at $4{ }^{\circ} \mathrm{C}$ for $15 \mathrm{~min}$, cells were incubated with a primary antibody anti-human SIRT1 (final dilution 1:100, Abcam, Cambridge, UK), re-suspended in PBS with 5\% normal goat serum for $1 \mathrm{~h}$ at room temperature, followed by a secondary PE-labeled goat anti-rabbit antibody (final dilution 1:1,000, Beckman Coulter, Milan, Italy). Control staining was performed using an isotype control IgG (R\&D Systems) in the exact same conditions. Intracellular fluorescence intensity was assessed using a FACSVerse cytometer and analyzed using BD FACSuite Software Application (BD Biosciences, Milan, Italy). To assess cell apoptosis, LPMC were cultured as indicated, and the percentage of annexin $\mathrm{V}$ and/or propidium iodide-positive cells was assessed by flow cytometry according to the manufacturer's instructions (Immunotech, Marseille, France).

LPMC were stained with PercP-labeled surface antibody against CD3 (BD Biosciences) for $30 \mathrm{~min}$ at $4{ }^{\circ} \mathrm{C}$. Intracellular staining was performed using fluoroscein isothiocyanate anti-human IFN- $\gamma$ antibody (BD Biosciences) and Alexa Fluor 647 anti-human IL-17A antibody (eBioscience) according to standard protocols. Appropriate isotype-matched control IgGs (BD Biosciences) were included in all experiments. All antibodies were used at a final dilution of 1:100. Cells were analyzed using a FACSCalibur cytometer and Cell-Quest Pro software (BD Bioscience).

Experimental colitis, LPMCs isolation and culture. For induction of chemically-induced colitis, $2 \mathrm{mg}$ of TNBS or $5 \mathrm{mg}$ of oxazolone in $35 \%$ ethanol were administered intrarectally to 7 -week-old male SJL mice (150 $\mu \mathrm{l}$ per mouse) as previously described. ${ }^{45}$ Controls consisted of mice treated with $150 \mu \mathrm{l}$ of $35 \%$ ethanol. In time-course experiments, mice with TNBS- or oxazolone-colitis were daily monitored for development of clinical signs of colitis (e.g., body weight changes) and killed at day 2, 4, and 6 .

To evaluate whether SIRT1 agonist regulates the production of inflammatory cytokines, LPMC isolated from mice with TNBS- or oxazolone-colitis ${ }^{46}$ were re-suspended in Roswell Park Memorial Institute 1640 medium supplemented with penicillin $\left(100 \mu \mathrm{g} \mathrm{ml}^{-1}\right)$, streptomycin $\left(100 \mu \mathrm{g} \mathrm{ml}^{-1}\right)$ and $10 \%$ fetal bovine serum (all from Lonza), pre-incubated with Cay10591 (10 $\mu \mathrm{m}$, Cayman Chemical) or DMSO (vehicle) for $1 \mathrm{~h}$, and then either stimulated with activating anti-CD3/CD28 antibody-coated beads (Miltenyi Biotec) or LPS (100 $\mathrm{ng} \mathrm{ml}^{-1}$ ) for $6 \mathrm{~h}$.

Cay10591 (4.5 $\mathrm{mg} \mathrm{kg}^{-1}$, Cayman Chemical) or DMSO (vehicle) were given in $500 \mu$ l of bicarbonate solution ( $\mathrm{pH}$ 9.5) via oral gavage 1 day before the administration of TNBS or oxazolone in the preventive model and 1 day after the administration of TNBS in the therapeutic model. To test the possible protective effects of a specific SIRT1 inhibitor, colitis was induced by intrarectal administration of $1 \mathrm{mg}$ of TNBS in $35 \%$ ethanol and EX527 $\left(10 \mathrm{mg} \mathrm{kg}^{-1}\right.$, Tocris) or DMSO (vehicle) was given in $500 \mu \mathrm{l}$ of bicarbonate solution ( $\mathrm{pH}$ 9.5) via oral gavage 1 day before the administration of TNBS. At the end of the experiments, colons were removed and collected for histology, protein, and RNA analysis. For TNBS- and oxazolone-induced colitis, the colitis score was assigned as described elsewhere. ${ }^{45}$

Immunohistochemistry on frozen sections. Immunohistochemistry was performed on frozen sections of colonic tissues taken from colitic mice. Tissue samples were cut, fixed first in $4 \%$ formalin solution, and then in ethanol. Blockade of endogenous peroxidase was performed by using $3 \% \mathrm{H}_{2} \mathrm{O}_{2}$ in methanol for $5 \mathrm{~min}$ at room temperature. Tissue sections were then incubated with a rabbit anti-mouse CD3 (final dilution 1:200, Spring Bioscience, Milan, Italy) or with a rat anti-mouse $\mathrm{F} 4 / 80$ (final dilution 1:500, eBioscience) for $1 \mathrm{~h}$ at room temperature followed by a highly sensitive biotinylated goat anti-rabbit IgG antibody (final dilution 1:200, Dako) or a biotinylated rabbit anti-rat IgG antibody (final dilution 1:1,000, Dako) for $30 \mathrm{~min}$ at room temperature, and finally with a horseradish peroxidase-conjugated streptavidin (Perkin Elmer, Monza, Italy). Immunoreactive cells were visualized using DAB (Dako) and lightly counterstained with hematoxylin. Isotype control sections were prepared under identical immunohistochemical conditions, replacing the primary antibody with a purified normal rabbit IgG control antibody (R\&D Systems). CD3- and F4/80-espressing cells were counted in at least three fields per section using IAS 2000 System (Delta Sistemi, Rome, Italy) and expressed as number of cells per high power field.

Enzyme-linked immunosorbent assay (ELISA). Colonic extracts were analyzed for mIFN $-\gamma$ content using a sensitive commercial ELISA kit (R\&D Systems).

Data analysis. Difference between groups will be compared using the Student's $t$-test, Mann-Whitney $U$-test and paired $t$-test.

SUPPLEMENTARY MATERIAL is linked to the online version of the paper at http://www.nature.com/mi

\section{ACKNOWLEDGMENTS}

This work was supported by "Fondazione Umberto Di Mario ONLUS" (Rome, Italy), Giuliani S.P.A. (Milan, Italy), "Associazione Nazionale per le Malattie Infiammatorie Croniche Intestinali (AMICI) Onlus" (Milan, Italy).

\section{AUTHOR CONTRIBUTIONS}

R.C. and I.M. performed cultures with human cells, analyzed cytokines expression in cells stimulated with Cay 10591 and Ex527, performed ELISA and immunoprecipitation, and conducted experimental models of colitis in mice. E.F. and A.C. contributed to isolated blood and mucosal mononuclear cells and performed immunohistochemical analysis. C.S. and I.M. performed flow cytometry staining. F.Z. and M.S. contributed to perform in vivo experiments. F.C., S.S., and L.B. collected patients. P.S. and G.S.S. collected and provided human specimens. F.P. and T.T.M. contributed to supervise parts of the project and to write the paper. G.M. designed the research, supervised the project, and wrote the manuscript.

\section{DISCLOSURE}

The authors declared no conflict of interest.

(c) 2014 Society for Mucosal Immunology

\section{REFERENCES}

1. Kaser, A, Zeissig, S \& Blumberg, R.S. Inflammatory bowel disease. Annu. Rev. Immunol. 28, 573-621 (2010).

2. Xavier, R.J. \& Podolsky, D.K. Unravelling the pathogenesis of inflammatory bowel disease. Nature 448, 427-434 (2007).

3. Strober, W, Fuss, I \& Mannon, P. The fundamental basis of inflammatory bowel disease. J. Clin. Invest. 117, 514-521 (2007).

4. Bouma, G \& Strober, W. The immunological and genetic basis of inflammatory bowel disease. Nat. Rev. Immunol. 3, 521-533 (2003).

5. Strober, W \& Fuss, I.J. Proinflammatory cytokines in the pathogenesis of inflammatory bowel diseases. Gastroenterology 140, 1756-1767 (2011).

6. Imai, S, Armstrong, C.M., Kaeberlein, M \& Guarente, L. Transcriptional silencing and longevity protein Sir2 is an NAD-dependent histone deacetylase. Nature 403, 795-800 (2000).

7. Landry, J. et al. The silencing protein SIR2 and its homologs are NAD-dependent protein deacetylases. Proc. Natl Acad. Sci. USA 97, 5807-5811 (2000).

8. Vaquero, A, Scher, M, Lee, D, Erdjument-Bromage, H, Tempst, P \& Reinberg, D. Human SirT1 interacts with histone $\mathrm{H} 1$ and promotes formation of facultative heterochromatin. Mol. Cell 16, 93-105 (2004).

9. Bordone, L \& Guarente, L. Calorie restriction, SIRT1 and metabolism: understanding longevity. Nat. Rev. Mol. Cell Biol. 6, 298-305 (2005). 
10. North, B.J. \& Verdin, E. Sirtuins: Sir2-related NAD-dependent protein deacetylases. Genome Biol. 5, 224 (2004).

11. Afshar, G\& Murnane, J.P. Characterization of a human gene with sequence homology to Saccharomyces cerevisiae SIR2. Gene 234, 161-168 (1999).

12. Zhang, J. et al. The type III histone deacetylase Sirt1 is essential for maintenance of T cell tolerance in mice. J. Clin. Invest. 119, 3048-3058 (2009).

13. Kume, S. et al. SIRT1 inhibits transforming growth factor beta-induced apoptosis in glomerular mesangial cells via Smad7 deacetylation. J. Biol. Chem. 282, 151-158 (2007).

14. Schug, T.T. et al. Myeloid deletion of SIRT1 induces inflammatory signaling in response to environmental stress. Mol. Cell. Biol. 30, 4712-4721 (2010).

15. Schreiber, S, Nikolaus, S \& Hampe, J. Activation of nuclear factor kappa B inflammatory bowel disease. Gut 42, 477-484 (1998).

16. Neurath, M.F. et al. Cytokine gene transcription by NF-kappa B family members in patients with inflammatory bowel disease. Ann. N. Y. Acad. Sci. 859, 149-159 (1998).

17. Fuss, I.J. et al. Disparate CD4 + lamina propria (LP) lymphokine secretion profiles in inflammatory bowel disease. Crohn's disease LP cells manifest increased secretion of IFN-gamma, whereas ulcerative colitis LP cells manifest increased secretion of IL-5. J. Immunol. 157, 1261-1270 (1996).

18. Brand, S. Crohn's disease: Th1, Th17 or both? The change of a paradigm: new immunological and genetic insights implicate Th17 cells in the pathogenesis of Crohn's disease. Gut 58, 1152-1167 (2009).

19. Monteleone, G. et al. Interleukin-21 enhances T-helper cell type I signaling and interferon-gamma production in Crohn's disease. Gastroenterology 128, 687-694 (2005).

20. Fina, D. et al. Regulation of gut inflammation and th17 cell response by interleukin-21. Gastroenterology 134, 1038-1048 (2008).

21. Heller, F. et al. Interleukin-13 is the key effector Th2 cytokine in ulcerative colitis that affects epithelial tight junctions, apoptosis, and cell restitution. Gastroenterology 129, 550-564 (2005).

22. Neurath, M.F., Fuss, I, Kelsall, B.L., Stuber, E \& Strober, W. Antibodies to interleukin 12 abrogate established experimental colitis in mice. J. Exp. Med. 182, 1281-1290 (1995).

23. Boirivant, M, Fuss, I.J., Chu, A \& Strober, W. Oxazolone colitis: a murine model of Thelper cell type 2 colitis treatable with antibodies to interleukin 4. J. Exp. Med. 188, 1929-1939 (1998).

24. Heller, F, Fuss, I.J., Nieuwenhuis, E.E., Blumberg, R.S. \& Strober, W. Oxazolone colitis, a Th2 colitis model resembling ulcerative colitis, is mediated by IL-13-producing NK-T cells. Immunity 17, 629-638 (2002).

25. Mudter, J. et al. The transcription factor IFN regulatory factor-4 controls experimental colitis in mice via T cell-derived IL-6. J. Clin. Invest. 118, 2415-2426 (2008)

26. Kong, S, McBurney, M.W. \& Fang, D. Sirtuin 1 in immune regulation and autoimmunity. Immunol. Cell Biol. 90, 6-13 (2012).

27. Tursi, A. et al. Musosal tumour necrosis factor alpha in diverticular disease of the colon is overexpressed with disease severity. Colorectal Dis. 14, e258-e263 (2012).

28. Caruso, R. et al. Analysis of the cytokine profile in the duodenal mucosa of refractory coeliac disease patients. Clin. Sci. (Lond) 126, 451-458 (2014).

29. Rajendrasozhan, S, Yang, S.R., Kinnula, V.L. \& Rahman, I. SIRT1, an antiinflammatory and antiaging protein, is decreased in lungs of patients with chronic obstructive pulmonary disease. Am. J. Respir. Crit. Care Med. 177, 861-870 (2008).

30. Biason-Lauber, A. et al. Identification of a SIRT1 mutation in a family with type 1 diabetes. Cell Metab. 17, 448-455 (2013).

31. Nayagam, V.M. et al. SIRT1 modulating compounds from high-throughput screening as anti-inflammatory and insulin-sensitizing agents. J. Biomol. Screen. 11, 959-967 (2006).

32. Napper, A.D. et al. Discovery of indoles as potent and selective inhibitors of the deacetylase SIRT1. J. Med. Chem. 48, 8045-8054 (2005).

33. Yang, H. et al. SIRT1 activators suppress inflammatory responses through promotion of $\mathrm{p} 65$ deacetylation and inhibition of NF-kappaB activity. PLOS One 7, e46364 (2012).

34. Gardner, P.J., Joshi, L, Lee, R.W., Dick, A.D., Adamson, P \& Calder, V.L. SIRT1 activation protects against autoimmune Tcell-driven retinal disease in mice via inhibition of IL-2/Stat5 signaling. J. Autoimmun. 42, 117-129 (2013).

35. Singh, U.P. et al. Resveratrol (trans-3,5,4'-trihydroxystilbene) induces silent mating type information regulation-1 and down-regulates nuclear transcription factor-kappaB activation to abrogate dextran sulfate sodiuminduced colitis. J. Pharmacol. Exp. Ther. 332, 829-839 (2010).

36. Martin, A.R., Villegas, I, Sanchez-Hidalgo, M \& de la Lastra, C.A. The effects of resveratrol, a phytoalexin derived from red wines, on chronic inflammation induced in an experimentally induced colitis model. Br. J. Pharmacol. 147, 873-885 (2006).

37. Martin, A.R., Villegas, I, La Casa, C \& de la Lastra, C.A. Resveratrol, a polyphenol found in grapes, suppresses oxidative damage and stimulates apoptosis during early colonic inflammation in rats. Biochem. Pharmacol. 67, 1399-1410 (2004).

38. Hilliard, B.A. et al. Critical roles of c-Rel in autoimmune inflammation and helper T cell differentiation. J. Clin. Invest. 110, 843-850 (2002).

39. Akimova, T. et al. Targeting sirtuin-1 alleviates experimental autoimmune colitis by induction of Foxp3 T-regulatory cells. Mucosal Immunol. advance online publication, 19 February 2014; doi:10.1038/mi.2014.10 (2014) (e-pub ahead of print).

40. Daperno, M. et al. Development and validation of a new, simplified endoscopic activity score for Crohn's disease: the SES-CD. Gastrointest. Endosc. 60, 505-512 (2004).

41. Schroeder, K.W., Tremaine, W.J. \& Ilstrup, D.M. Coated oral 5-aminosalicylic acid therapy for mildly to moderately active ulcerative colitis. A randomized study. N. Engl. J. Med. 317, 1625-1629 (1987).

42. Marsh, M.N. Gluten, major histocompatibility complex, and the small intestine. A molecular and immunobiologic approach to the spectrum of gluten sensitivity ('celiac sprue'). Gastroenterology 102, 330-354 (1992).

43. Monteleone, G. et al. Interleukin 12 is expressed and actively released by Crohn's disease intestinal lamina propria mononuclear cells. Gastroenterology 112, 1169-1178 (1997).

44. Caruso, R. et al. A functional role for interleukin-21 in promoting the synthesis of the T-cell chemoattractant, MIP-3alpha, by gut epithelial cells. Gastroenterology 132, 166-175 (2007).

45. Boirivant, M. et al. Inhibition of Smad7 with a specific antisense oligonucleotide facilitates TGF-beta1-mediated suppression of colitis. Gastroenterology 131, 1786-1798 (2006).

46. Stolfi, C. et al. Involvement of interleukin-21 in the regulation of colitisassociated colon cancer. J. Exp. Med. 208, 2279-2290 (2011). 